\title{
Structure-Based Virtual Screening, Molecular Docking, Molecular Dynamics simulation of VEGF inhibitors for the clinical treatment of Ovarian Cancer
}

Sourav Mukherjee

Eminent Biosceinces

Mohnad Abdalla

Shandong University Cheeloo College of Medicine

Manasi Yadav

Eminent Biosciences

Maddala Madhavi

Department of Zoology, Osmania University

Anushka Bhrdwaj

Eminent Biosciences

Ravina Khandelwal

Eminent Biosciences

Leena Prajapati

Eminent Biosciences

Aravind Panicker

Eminent Biosciences

Aashish Chaudhary

Eminent Biosciences

Ashraf Al-Brakati

Taif University

Tajamul Hussain

King Saud University

Anuraj Nayarisseri ( $\nabla$ anuraj@eminentbio.com )

Alagappa University

Sanjeev Kumar Singh

Alagappa University

Research Article 
Keywords: Ovarian Cancer, VEGF, VEGF inhibitors, Molecular Docking, Virtual Screening, Molecular Dynamics, ADMET studies, Egg Plot

Posted Date: March 2nd, 2022

DOI: https://doi.org/10.21203/rs.3.rs-840860/v2

License: (c) (1) This work is licensed under a Creative Commons Attribution 4.0 International License. Read Full License

Version of Record: A version of this preprint was published at Journal of Molecular Modeling on March 24th, 2022. See the published version at https://doi.org/10.1007/s00894-022-05081-3. 


\section{Abstract}

Vascular Endothelial Growth Factor (VEGF) and its receptor play an important role both in physiologic and pathologic angiogenesis, which is identified in ovarian cancer progression and metastasis development. The aim of the present investigation is to identify a potential Vascular Endothelial Growth Factor inhibitor which is playing a crucial role in stimulating the immunosuppressive microenvironment in tumour cells of the ovary and to examine for an effectiveness of identified inhibitor for the treatment of ovarian cancer using various in-silico approaches. 12 established VEGF inhibitors were collected from various literature. The compound AEE788 displays the great affinity towards the target protein as a result of docking study. AEE788 was further used for structure-based virtual screening in order to obtain a more structurally similar compound with high affinity. Among the 80 Virtual screened compounds, CID 88265020, explicates much better affinity than established compound AEE788. Based on Molecular Dynamics Simulation, pharmacophore and comparative toxicity analysis of both the best-established compound and the best virtual screened compound displayed a trivial variation in associated properties. The virtual screened compound CID 88265020 have a high affinity with the lowest re-rank score, and holds a huge potential to inhibit the VGFR and can be implemented for prospective future investigations in Ovarian Cancer.

\section{Introduction:}

Ovarian cancer is the most lethal gynaecologic malignancy and it is a type of disease in which malignant (cancer) cells form in the tissue coating the ovary. Ovarian cancer is the seventh most frequent cancer among women and among other cancers, ovarian cancer is one among the top ten regular reasons for death from cancer throughout the globe[1]. The prediction stated that due to ovarian cancer there were > 120,000 deaths worldwide in every year [2]. Statistically half of all ovarian cancers are begin in women of the age of 65 years or greater and for this reason, limited survivability possibility for women [1]. Maximum ovarian cancers develop after menopause. Women who have ovulated more over their lifetime are at an extended risk of ovarian cancer. Some combination of surgery, radiation therapy, and chemotherapy during the primary stage of ovarian cancer exhibits the overall five-year survival rate in the Western countries is around 35-45\% [3]. Ovarian carcinoma is the most frequent type of ovarian cancer. Five chief subtypes are there in ovarian carcinoma in which high-grade serous carcinoma is the most typical type and germ cell tumors, sex cord-stromal tumors are the less typical types of ovarian cancer. The initial mutation in BRCA1 and BRCA2, DNA mismatch genes lead to ovarian cancer [3]. The risk of ovarian cancer rises in those women who possess a family history of ovarian cancer [3]. BRCA mutations are associated with high-grade serious non-mucinous epithelial ovarian cancer whereas Lynch syndrome is initiated by mutations in mismatch repair genes[3]. Therefore, there is an extreme necessity to identify newer inhibitors and drugs for the betterment of survival in ovarian cancer. Vascular Endothelial Growth Factor A (VEGF A) which was formally identified as VEGF, is an essential regulator of vasculogenesis and angiogenesis in both normal tissues, and tumors cells [4]. VEGF $A$ is also crucial for provoking the immunosuppressive microenvironment in tumors[5].VEGF further enhances cell survival, proliferation, 
and migration. Investigations have disclosed the over-expression of VEGF in ovarian cancer. The expression of VEGF and IL-8 in ovarian cancer are following the transcriptional regulation of nuclear factor kappa-B (NF-kB)[6]. VEGFR 1(Flt-1) and VEGFR2(Flk-1/kinase domain receptor) are the two most important members of the VEGFR family which plays a significant role in angiogenesis[7]. VEGFR 2 reconciles the angiogenic and permeability-enhancing effect of VEGF while VEGFR 1 performs a role in angiogenesis by selecting bone marrow-derived cells and monocytes into the tumor vasculature[7]. Bevacizumab is a recombinant monoclonal antibody that inhibits the VEGF signaling pathway by binding to circulating VEGF $A$ and has been widely appraised in ovarian cancer treatment [8]. Still, various inhibitor investigations are progressing on to direct antagonistic against VEGF and its mechanisms, including different signaling pathways. Most of these inhibitors target the autophosphorylation of VEGFR 2, a key step in the VEFG signaling pathway, which leads to angiogenesis,[8]. The present study focus on drug discovery which exhibits inhibitory impacts on VEGF protein and therefore, ascents apoptosis of ovarian cancer.

\section{Results}

\subsection{Protein and ligand preparation}

The signaling protein, Vascular Endothelial Growth Factor Receptor 2 (VEGFR-2 PDB ID: 3V2A), obtained from protein database bank, was cleaned using Schrödinger module before visualization of its X-ray diffraction data with RasMol software; depicted in ribbon and backbone model [Fig. 1]. The target protein has two chains with 280 groups of 2114 atoms and a total of 2160 bonds. There are three spring-shaped alpha-helices in red, and 25 beta-strands denoted with blue and the junction between alpha-helices and beeta sheets are loops and turns. The binding of the ligand could be anticipated from protein-folds of the target VEGF protein. Before docking, ligand preparation was done in the LigPrep module of Schrodinger suite, 2013.

\subsection{Molecular Docking}

The docking results of the 12 established compounds in the first cavity which is the largest cavity of the target protein VEGF listed in Table 1. Among all the established compounds, AEE788 (PubChem ID 10297043) has resulted as the best-established compound as it shows the lowest re-rank score among all compounds and has the highest affinity towards the VEGF. AEE788 is a type 1 tyrosine kinase inhibitor of the vascular endothelial growth factor receptor (VEGFR) and epidermal growth factor receptor (ErbB)having potential anti-angiogenic activity[9]. The compound also has high-affinity and physicochemical properties such as molecular weight $440.595 \mathrm{~g} / \mathrm{mol}$, hydrogen bond donor count 2 and hydrogen bond acceptor count 5 , and logP value of 4.6. The compound holds a re-rank score-95.9802 with the $\mathrm{H}$-bond interaction score of -2.5. Hence, this compound was identified as the best-established compound against the target protein VEGF. 
Table 1

Established compounds docking study result.

\begin{tabular}{|llllll|}
\hline Ligand & Filename & $\begin{array}{l}\text { MolDock Score } \\
(\mathrm{KJ} / \mathrm{mol})\end{array}$ & $\begin{array}{l}\text { Re-rank } \\
\text { Score(KJ/mol) }\end{array}$ & H-Bond & $\begin{array}{l}\text { MW } \\
(\mathbf{g} / \mathrm{mol})\end{array}$ \\
\hline 10297043 & {$[02] 10297043$} & -121.765 & -95.9802 & -2.5 & 440.583 \\
\hline 123631 & {$[00] 123631$} & -116.826 & -91.3569 & -1.27851 & 446.902 \\
\hline 9933475 & {$[01] 9933475$} & -121.08 & -90.3479 & -2.26465 & 450.505 \\
\hline 216239 & {$[04] 216239$} & -106.066 & -90.2369 & -4.5783 & 464.825 \\
\hline 9809715 & {$[03] 9809715$} & -130.606 & -88.876 & -1.88135 & 539.625 \\
\hline 123631 & {$[01] 123631$} & -106.039 & -87.1955 & -1.95681 & 446.902 \\
\hline 9911830 & {$[00] 9911830$} & -120.891 & -86.9845 & -8.73156 & 454.863 \\
\hline 9911830 & {$[03] 9911830$} & -116.349 & -85.2625 & -1.99962 & 454.863 \\
\hline 9911830 & {$[01] 9911830$} & -116.111 & -84.7526 & -1.6096 & 454.863 \\
\hline 10297043 & {$[04] 10297043$} & -114.998 & -84.607 & 0 & 440.583 \\
\hline 10113978 & {$[00] 10113978$} & -110.567 & -84.4218 & -2.45945 & 437.518 \\
\hline 9933475 & {$[02] 9933475$} & -112.536 & -84.2488 & -2.42747 & 450.505 \\
\hline
\end{tabular}

\subsection{Virtual screening}

Similarity search of the best-established compound against PubChem database resulted in 80 compound structures that gave $a=>95$ similarity percentage. Table 2 records the top 11 compounds that exhibit the greatest affinity to the target protein VEGF. The compound with PubChem ID 88265020 was recognized to hold the lowest re-rank score and was therefore confirmed as a compound with the greatest affinity towards the targeted protein. Some of the physical properties of the virtual screened compound comprise of molecular weight of $569.783 \mathrm{~g} / \mathrm{mol}$, hydrogen bond donor count of 5 , hydrogen bond acceptor count of 7 , and a $\log P$ value of 6.1. The re-rank score of this compound attains at -112.171 and the $\mathrm{H}$-bond interaction score is -8.6315 . Therefore, between a total of 80 compounds, the compound PubChemID88265020 possess a much greater ability to inhibit the target protein VEGF against ovarian cancer subjected to further analysis. 
Table 2

Docking study result for virtual screened compounds with reference to high-affinity Virtual screened compounds with reference to high affinity established compound AEE788 (PubChem ID 10297043)

\begin{tabular}{|llllll|}
\hline Ligand & Filename & $\begin{array}{l}\text { MolDock Score } \\
(\mathrm{KJ} / \mathrm{mol})\end{array}$ & $\begin{array}{l}\text { Rerank Score } \\
(\mathrm{KJ} / \mathrm{mol})\end{array}$ & H-Bond & $\begin{array}{l}\text { MW } \\
(\mathbf{g} / \mathrm{mol})\end{array}$ \\
\hline 88265020 & {$[00] 88265020$} & -149.521 & -112.171 & -8.6315 & 569.783 \\
\hline 88265020 & {$[01] 88265020$} & -149.487 & -109.471 & -1.81064 & 569.783 \\
\hline 88265020 & {$[04] 88265020$} & -128.011 & -101.733 & -3.45831 & 569.783 \\
\hline 71313049 & {$[00] 71313049$} & -125.348 & -100.642 & -7.07561 & 440.583 \\
\hline 44629455 & {$[00] 44629455$} & -131.699 & -99.8896 & -2.5 & 442.599 \\
\hline 10297042 & {$[03] 10297042$} & -128.873 & -99.1998 & -0.10172 & 440.583 \\
\hline 69170098 & {$[04] 69170098$} & -122.43 & -98.656 & -2.5 & 412.53 \\
\hline 69232929 & {$[00] 69232929$} & -125.312 & -98.3018 & -7.16336 & 412.53 \\
\hline 16071547 & {$[01] 16071547$} & -128.745 & -97.5661 & -3.87498 & 516.679 \\
\hline 16071547 & {$[03] 16071547$} & -118.562 & -96.8667 & 0 & 516.679 \\
\hline 69232929 & {$[01] 69232929$} & -127.435 & -96.8654 & -4.88497 & 412.53 \\
\hline
\end{tabular}

\subsection{Molecular Dynamics Simulation}

The dynamic simulation of a molecule provides details of probable conformational changes over a trajectory, comparable to the biological environment. The simulation result is analyzed over structural analysis by RMSD and RMSF, ligand properties, and protein-ligand interaction. The root mean square deviation (RMSD) graph suggests structural stability of protein-ligand interaction, lower RMSD confers greater stability. The Root Mean Square fluctuation (RMSF) graph indicates the mobility of protein residue. The inter-residue interaction for virtual screened best compounds shows to be more stable compared to best-established compounds. The protein RMSD for AEE788 is variable over a range of 3$11 \AA$ with a sharp deviation at $119 \mathrm{~ns}$, and the ligand graph follows the estimated trend as protein except for a deviation between $40-50 \mathrm{~ns}$ and another undulation at $80 \mathrm{~ns}$ modulating the average RMSD value from 2 to $4 \AA$ [Fig. 3(I)]. This suggests the VEGFR complex with AEE788 interaction is volatile; confirmed with the RMSF graph for AEE788, ranged over 1-7.5 $\AA$ where frequent peaks imply flexible amino acids are on protein's $\mathrm{C} \otimes$ backbone. [Fig. 3 (II)]. The RMSD graph for protein-lead compounds is steadier comparatively. In the VEGFR complex with virtual screened compound, protein RMSD fluctuates from 2 to $7.2 \AA$ at frequent intervals and lead compound RMSD spans over $2.5-20 \AA$ with recurrent variation over the trajectory. [Fig. 3(III)]. It is to be noted that the mean value of interaction for VEGFR complex with virtual screened compounds is less than VEGFR complex with AEE788 and scant veering over the trajectory, hence, more stable. Besides, there are relatively more sharp peaks in the RMSF graph of VEGFR 
complex with virtual screened compounds which allude to more flexibility in protein's $\mathrm{C} \mathbb{}$ backbone. [Fig. 3(IV)].

\subsubsection{Protein-Ligand interaction}

Molecular dynamic simulation gives insight into probable protein-ligand interaction for established compound and virtual screened compound, depicted with histogram and heatmap [Fig. 4]. The interface between protein and ligand comprises four types of bonds: hydrogen bonds, hydrophobic interaction, ionic bonds, and water bridges; hydrogen bond plays a significant role in ligand binding and drug specificity. The histogram for protein-established compound propones its hydrophobic nature which means pi-cation, pi-pi, and other nonspecific interactions are present. The amino acid residues PRO_49, MET_78, MET_81, HIS_133, TYR_165, MET_197, ALA_202 and ILE_215 exhibits hydrophobic interaction[Fig. 4(A)].The hydrogen bonding which strongly influences drug specificity, metabolization, and adsorption is by few residues LYS_48, GLN_79, LEU_151, and TYR_165; alongside, only GLU_30 and LEU_151 residue show ionic interaction inferring the established compound is not many ligands specific. However, residues scilicet, GLU_30, LYS_48, GLN_79, GLN_132, SER_153 are forming water bridges (hydrogen-bonded protein-ligand interaction mediated by water molecules). The [Fig. 4(B)] is a heatmap for individual residue interaction with protein over a trajectory frame, the intensity of color enumerates interactions of amino acids and there are few residues with more than two contacts with the ligand molecule. The residue HIS_133 showed 43\% interaction occupancy by forming hydrophobic bonding with the ligand [Fig. 4(C)].

The protein-lead compound interaction, depicted in [Fig. 5] suggest overwhelming hydrophobic interaction and water bridges. This compound shows more hydrogen bonding, owing to the hydroxylamine octyl chain. TYR_165 asserts strongest hydrophobic interaction along with PRO_166, TYR_194, MET_197, PHE_199 residues [Fig. 5(A)]. The virtual screened compound is showing an ionic bond by residue GLU_167, plausibly with an additional hydroxylamine functional group. And residues like MET_213 and GLN_132 are forming hydrogen bonds by back donating. The water bridges are formed by residues TYR_165, GLU_167, TYR_194, GLN_210. This also connotes this surface is exposed for binding. The heatmap for this interaction insinuates only a few residues like HIS_133, GLN_132, TYR_165, GLN_210, SER_211, and ILE_215 have a greater number of contacts over the trajectory frame compared to others. The number of specific contacts made by protein with ligand varies from zero to nine [Fig. 5(B)] and an average number of contacts between protein and virtual screened compound is more when compared to VEGF complex with best-established compound AEE788. Figure 5(C) shows the ligand interaction with amino acids of VEGF receptor.

\subsubsection{Ligand property}

The ligand property was analyzed over a range of parameters: Root Mean Square Deviation (RMSD), the radius of gyration (rGyr), molecular surface area (MolSA), solvent accessible surface area (SASA), and polar surface area (PSA), giving structural details. The RMSD graph demonstrating the stability of the 
compound, for established compounds is wavering in the ranged of $1-3 \AA$ with a mean near $2 \AA$. The radius of gyration ascribes the distance of an atom from the center of mass of the molecule, in order to obtain the same moment of inertia; it provides insight into the overall dimension of the protein. In this complex rGyr value is between 4.8-6 $\AA$ with a mean at 5.3 $\AA$. The molecular surface area was calculated using a 1.4 probe radius, it pertains on Van der Waals surface area. The MolSA is ranged between 424$448 \AA^{2}$ with a mean area of $440 \AA^{2}$. The solvent surface area is a water-accessible area that ranges from 200 to $800 \AA^{2}$ and is highly variable with two peaks around $40 \mathrm{~ns}$ and $80 \mathrm{~ns}$. The polar surface area is surface accessible for binding of ionic molecules and the PSA value was stable over the trajectory with a mean at $80 \AA^{2}$. [Fig:6]

The virtual screened compound's RMSD trajectory is erratic range from $1-4.5 \AA$ with a mean at $3.0 \AA$. The rGyr is stable after 20 ns with a mean at $8 \AA$ ranging between $6-9 \AA$, which is higher than the established compound. The molecular surface area ranged from 550 to $600 \AA^{2}$ with fluctuation at $18 \mathrm{~ns}$ stability thereafter with the equilibrium of approximately $595 \AA^{2}$ which is more compared to the established compound (432 $\AA^{2}$ ). Also, the solvent-accessible surface area is more erratic varying from 400 to $750 \AA^{2}$, and mean polar surface area is $160 \AA^{2}$. As the surface area of virtual screened compounds is relatively more compared to established compounds, attributed to the octyl hydroxylamine chain, the mean value of surface areas and radius of gyration is also higher and it also gives more flexibility to ligands which could be seen from the RMSD graph. [Fig. 7]. The ligand property of virtual screened compound (PubChem CID: 88265020) is studied more with pharmacophore mapping.

\subsection{Drug - Drug Comparative study}

Drug-drug Comparative study records the MolDock Scores and re-ranks scores of the best-established compound and the best virtual screened compound against the target protein VEGF on ovarian cancer [Table 3]. The table indicates that the best-virtual screened compound holding PubChem ID: 88265020 has a higher binding affinity to the target VEGF protein if correlated to the best-established compound AEE788 (PubChem ID: 10297043) due to a lower re-rank score counts - 112.158. The compound holding PubChem ID 88265020 discloses lower MolDock Scores and re-rank scores for several additional essential characteristics like External ligand interactions, protein-ligand interactions, hydrogen bonds which intimates that this compound occupies a greater affinity to the VEGF protein. A steric value measured by PLP (Piecewise Linear Potential) is lower for the best virtual screened compound whereas, in the case of the LJ12-6(Leonard-Jones approximation) method, it shows a lower value for the bestestablished compound. Therefore, it illustrates that both the compounds have comparable possible inhibition against the VEGF protein. 
Table 3

Drug-Drug comparative study

\begin{tabular}{|c|c|c|c|c|}
\hline \multirow[b]{2}{*}{ Energy overview: Descriptors } & \multicolumn{2}{|c|}{$\begin{array}{l}\text { Established Compound } \\
\text { PubChem ID: } 10297043\end{array}$} & \multicolumn{2}{|c|}{$\begin{array}{l}\text { Virtual Screened Compound } \\
\text { (PubChem ID: 88265020) }\end{array}$} \\
\hline & $\begin{array}{l}\text { MolDock } \\
\text { Score }\end{array}$ & $\begin{array}{l}\text { Rerank } \\
\text { Score }\end{array}$ & $\begin{array}{l}\text { MolDock } \\
\text { Score }\end{array}$ & $\begin{array}{l}\text { Rerank } \\
\text { Score }\end{array}$ \\
\hline Total Energy & -121.763 & -95.967 & -149.505 & -112.158 \\
\hline External Ligand interactions & -143.736 & -122.464 & -174.491 & -144.108 \\
\hline Protein - Ligand interactions & -143.736 & -122.464 & -174.491 & -144.108 \\
\hline Steric (by PLP) & -141.236 & -96.888 & -165.861 & -113.781 \\
\hline Steric (by LJ12-6) & & -23.596 & & -23.493 \\
\hline Hydrogen bonds & -2.5 & -1.98 & -8.63 & -6.835 \\
\hline $\begin{array}{l}\text { Hydrogen bonds (no } \\
\text { directionality) }\end{array}$ & & 0 & & 0 \\
\hline Electrostatic (short range) & 0 & 0 & 0 & 0 \\
\hline Electrostatic (long range) & 0 & 0 & 0 & 0 \\
\hline Cofactor - Ligand & 0 & 0 & 0 & 0 \\
\hline Steric (by PLP) & 0 & & 0 & \\
\hline Steric (by LJ12-6) & & 0 & & 0 \\
\hline Hydrogen bonds & 0 & 0 & 0 & 0 \\
\hline Electrostatic & 0 & 0 & 0 & 0 \\
\hline Water - Ligand interactions & 0 & 0 & 0 & 0 \\
\hline Internal Ligand interactions & 21.973 & 26.497 & 24.986 & 31.95 \\
\hline Torsional strain & 7.658 & 7.183 & 16.15 & 15.148 \\
\hline Torsional strain (sp2-sp2) & & 3.952 & & 3.436 \\
\hline Hydrogen bonds & & 0 & & 0 \\
\hline Steric (by PLP) & 14.315 & 2.462 & 8.836 & 1.52 \\
\hline Steric (by LJ12-6) & & 12.9 & & 11.845 \\
\hline Electrostatic & 0 & 0 & 0 & 0 \\
\hline Soft Constraint Penalty & 0 & & 0 & \\
\hline Search Space Penalty & 0 & & 0 & \\
\hline
\end{tabular}




\subsection{Pharmacophore mapping}

Pharmacophore mapping provides the quintessential systemic spatial feature of the molecular interaction of the ligand with the target receptor, apart from the method of molecular docking, for understanding the interactive characterization and provide a factual query on the suitable target interface. It imitates the aligned poses of the molecule and identifies the apt interaction between the target protein and the lead compound. Owing to this admirable affinity and good interaction profile of the virtual screened compound (PubChem ID 88265020), the study was conducted to obtain various kinds of analyzed pharmacophore interactions. The desired compounds were in .sdf format for pharmacophore studies. The residue interaction of the best virtual screened compound (PubChem ID 88265020) in the cavity of VEGF protein was studied.

The Van der Waals coupling of the VEGF protein structure and the virtual screened compound (PubChem ID 88265020) is displayed in [Fig. 8]. The electrostatic interaction is shown by Gly196, Met197, His133, Tyr194, Tyr165, Lys48, Met213 and Gln132 residues, symbolically encircled in pink, these residues are also involved in hydrogen bonding; whereas Pro49, Ala195, Pro166, Glu167, lle215, and lle212 residues are involved in Van der Waals interactions, encircled in green. The residues represented with various shades and size blue halo around it infers the solvent-accessible surface of an interacting residue such as Tyr165 and Met213 residues: the size of the halo is proportional to the accessible surface area. Furthermore, the solvent-accessible surface of an atom is represented by a blue halo around the atom and the diameter of the circle is proportional to the solvent-accessible surface. Met213, GIn132, and Tyr194 show the Hydrogen bond interactions with amino acid main chains are represented by a green dashed arrow directed towards the electron donor. Tyr165 with the compound shows pi-pi interaction is represented by an orange line with the pi symbol indicating the interaction.

The H-bond interactions of the virtual screened compound (PubChem ID: 88265020) having the lowest rerank score possessing immense affinity at the active sites of the VEGF protein cavity [Fig. 9]. Hydrophilic and hydrophobic, electrostatic, and $\mathrm{H}$-bond interactions are examples of the pharmacophoric characteristics of the ligand-receptor interaction. Figure 8 represents the compound binding of the specific amino acid residues of the VEGF protein through a hydrogen bond. An amino acid LYS 286 , PHE 36, GLN 79 and LYS 48 residue shows the four H-bond interactions represented by the black and yellow dotted line. The virtual screened compound (Pubchem ID: 88265020) has a number of hydrogen bond interactions as compared to the established compound, AEE788 (PubChem ID 10297043).

The electrostatic interaction of virtual screened compound (PubChem ID-88265020) [Fig. 10] manifests that the clusters of charged and polar residues, that are detected on protein-protein interfaces, may intensify the stability of the complex; though the net effect of electrostatics is generally destabilizing. The virtual screened compound (PubChem ID-88265020) with VEGF protein having a high affinity was embedded in the protein cavity. The positive and negative areas of the protein are demonstrated by two types of variant colors: the red color evinces the electro-negativity zone, whereas the electropositive zone with blue color. The electrically neutral zone is shown with a white-colored surface. Most of the atoms of

Page $10 / 40$ 
the target compound in the protein cavity were observed to be biased towards the blue color zone inferring the high electro-positivity.

Figure 11 represents the aromatic interactions with the most effective virtual screened compound (PubChem ID-88265020). The aromatic interaction is indicative of the effective binding stability of the compound with protein. The aromatic conformation imparts an effect on the function of the complex molecule. The identified virtual screened compound (PubChem ID: 88265020) shows a higher affinity aromatic interaction in the VEGF protein binding site. In [Fig. 10], the blue color symbolizes the edges of the protein cavity with light shade surfaces and shade surfaces having the color orange signifying the face. Here an amino acid His133, Met197, Gly196, Tyr165, Pro166, Ala195, Tyr194, Leu161, and Glu132 residues are showing aromatic interaction. These interactions coincide with molecular dynamic observation.

\subsection{ADMET studies-Pharmacological and metabolic properties}

AdmetSAR software was used to estimates various ADMET properties of the best-established compound AEE788 (PubChem ID 10297043) and the best virtual screened compound holding PubChem ID: 88265020 . The SwissADME software briefing six essential properties of oral bioavailability are represented with bioavailability radar for best of the two best-established compounds and virtuallyscreened compounds [Fig. 12]; the pink region in radar is a range of optimal value.

\subsubsection{Absorption prediction of the compound}

After the drug administration, ADMET blood-brain barrier model foretells the penetration of the drug across Blood Brain Barrier(BBB) [Table 4]. The intestinal absorption of a drug is prognosticated by HIA after oral administration. While comparing with the established drug, the ADMET absorption level of the compound is revealing good absorption. A monolayer tissue culture of an ideal human colon adenocarcinoma (referred as, Caco-2) is acknowledged as a standard for testing drug permeability in drug discovery, the foretold effects exhibit permeability in both cases. P-glycoprotein is associated with many purposes like clearance of xenobiotic compounds, transport of small molecules to vital areas, and present in multidrug-resistant malignant cells: its inhibition can be utilized to decrease the multidrugresistant characteristic. It is also an $A B C$ transporter. On analysis, compounds displayed excellent circumstances in this case. Also, the inhibitory characteristics against P-glycoprotein imply that the compound can be applied for the treatment of multidrug-resistant cancer cell lines.

\subsubsection{ADMET aqueous solubility}

In the bioavailability of the drug, the aqueous solubility acts as an essential parameter. At $25^{\circ} \mathrm{C}$, it foretells the solubility of the compound in water. Compound holding a PubChem ID: 88265020 confers an almost excellent aqueous solubility level by displaying a value of -2.7704 [Table 5]. It indicates that the 
virtual screened compound holding a PubChem ID: 88265020 is more polar and more soluble in the aqueous medium correlated with the established compound AEE788 (PubChem ID 10297043).

\subsubsection{Compound metabolism}

In this section, the expression of the relevant isoforms of cytochrome P450 as a substrate or inhibitor of the virtual screened compound is prognosticated. The compound acts as non-substrate of 2C9, 2D6, and 3A4 isoform of cytochrome P450. In inhibition forecast, it did not expose any inhibitory outcome in 2C9, 2D6, 2C19, and 3A4 isoforms but it displayed in 1A2 isoform of CYP450. Comparison of the score intimates that the virtual screened compound is sufficiently metabolized with respect to cytochrome P450 while comparing with the established compound.

\subsubsection{Toxicity prediction}

The mutagenicity of a compound is determined by the AMES toxicity test. In the case of the established compound, a negative AMES toxicity test result was designated by the processed ligand compound which indicates that the compound is non-mutagenic. Also, the virtual screened compound is noncarcinogenic and it is showing a lower value contrasted to the established compound. In acute oral toxicity prediction, the virtual screened compound is displaying a slightly higher score compared to the established compound. LD50 dose in the rat model which is the most significant parameter is calculated applying admetSAR. A compound is more lethal when it holds a lower LD50 value compared to a compound having a higher LD50 value. Additionally, it is observed that the virtual screened compound had a relatively comparable LD50 value when differentiating with the established compound (2.63 and 2.77 sequentially). The graphical representation based on parameters HIA, BBB, ADME toxicity, and LD50 is in Fig. 13. 
Table 4

Corresponding ADMET profile analysis of the best-established inhibitor (PubChemID:10297043) and best virtual screened compound holding Pub-ChemID 88265020

\begin{tabular}{|lllll|}
\hline & \multicolumn{2}{l}{$\begin{array}{l}\text { Established Compound AEE788 } \\
\text { (PubChem ID: 10297043) }\end{array}$} & \multicolumn{2}{l|}{$\begin{array}{l}\text { Virtual Screened Compound } \\
\text { PubChem ID: 88265020 }\end{array}$} \\
\hline Model & Result & Probability & Result & Probability \\
\hline Absorption & & & & \\
\hline Blood-Brain Barrier & BBB+ & 0.8872 & BBB+ & 0.9262 \\
\hline $\begin{array}{l}\text { Human Intestinal } \\
\text { Absorption }\end{array}$ & HIA+ & 0.9964 & HIA+ & 0.996 \\
\hline Caco-2 Permeability & Caco2- & 0.5453 & Caco2- & 0.638 \\
\hline $\begin{array}{l}\text { P-glycoprotein } \\
\text { Substrate }\end{array}$ & Substrate & 0.8334 & Substrate & 0.7012 \\
\hline $\begin{array}{l}\text { P-glycoprotein } \\
\text { Inhibitor }\end{array}$ & Inhibitor & 0.5299 & Non-inhibitor & 0.543 \\
\cline { 2 - 4 } & Inhibitor & 0.7895 & Inhibitor & 0.6269 \\
\hline $\begin{array}{l}\text { Renal Organic Cation } \\
\text { Transporter }\end{array}$ & Inhibitor & 0.6161 & Non-inhibitor & 0.5375 \\
\hline
\end{tabular}




\begin{tabular}{|lllll|}
\hline & Established Compound & & \multicolumn{2}{l|}{ Virtual Screened Compound } \\
\hline Distribution & Result & Probability & Result & Probability \\
\hline $\begin{array}{l}\text { Subcellular } \\
\text { localization }\end{array}$ & Nucleus & 0.5677 & Mitochondria & 0.4583 \\
\hline Metabolism & & & & \\
\hline $\begin{array}{l}\text { CYP450 2C9 } \\
\text { Substrate }\end{array}$ & Non-substrate & 0.8446 & Non-substrate & 0.7538 \\
$\begin{array}{l}\text { CYP450 2D6 } \\
\text { Substrate }\end{array}$ & Non-substrate & 0.696 & Non-substrate & 0.7285 \\
\hline $\begin{array}{l}\text { CYP450 3A4 } \\
\text { Substrate }\end{array}$ & Non-substrate & 0.5221 & Non-substrate & 0.5396 \\
\hline $\begin{array}{l}\text { CYP450 1A2 } \\
\text { Inhibitor }\end{array}$ & Non-inhibitor & 0.597 & Inhibitor & 0.6884 \\
\hline $\begin{array}{l}\text { CYP450 2C9 } \\
\text { Inhibitor }\end{array}$ & Non-inhibitor & 0.7066 & Non-inhibitor & 0.8274 \\
\hline $\begin{array}{l}\text { CYP450 2D6 } \\
\text { Inhibitor }\end{array}$ & Non-inhibitor & 0.7209 & Non-inhibitor & 0.8123 \\
\hline $\begin{array}{l}\text { CYP450 2C19 } \\
\text { Inhibitor }\end{array}$ & Non-inhibitor & 0.6596 & Non-inhibitor & 0.8159 \\
\hline $\begin{array}{l}\text { CYP450 3A4 } \\
\text { Inhibitor }\end{array}$ & Non-inhibitor & 0.8663 & Non-inhibitor & 0.8503 \\
\hline $\begin{array}{l}\text { CYP Inhibitory } \\
\text { Promiscuity }\end{array}$ & $\begin{array}{l}\text { High CYP Inhibitory } \\
\text { Promiscuity }\end{array}$ & 0.8082 & Low CYP Inhibitory & 0.5736 \\
\hline
\end{tabular}




\begin{tabular}{|lllll|}
\hline & \multicolumn{2}{l}{ Established Compound } & \multicolumn{2}{l|}{ Virtual Screened Compound } \\
\hline Excretion & Result & Probability & Result & Probability \\
\hline Toxicity & & & & \\
$\begin{array}{l}\text { Human Ether-a-go-go-Related } \\
\text { Gene Inhibition }\end{array}$ & Weak inhibitor & 0.6689 & Strong inhibitor & 0.6529 \\
\cline { 2 - 5 } & Inhibitor & 0.8604 & Inhibitor & 0.75 \\
\hline AMES Toxicity & Non AMES toxic & 0.7699 & AMES toxic & 0.5252 \\
\hline Carcinogens & Non-carcinogens & 0.8755 & Non- & 0.7132 \\
\hline Fish Toxicity & High FHMT & 0.9324 & High FHMT & 0.5096 \\
\hline $\begin{array}{l}\text { Tetrahymena Pyriformis } \\
\text { Toxicity }\end{array}$ & High TPT & 0.9706 & High TPT & 0.9026 \\
\hline Honey Bee Toxicity & Low HBT & 0.8444 & Low HBT & 0.8037 \\
\hline Biodegradation & $\begin{array}{l}\text { Not ready } \\
\text { biodegradable }\end{array}$ & 0.9975 & $\begin{array}{l}\text { Not ready } \\
\text { biodegradable }\end{array}$ & 0.9963 \\
\hline Acute Oral Toxicity & III & 0.5151 & III & 0.5992 \\
\hline Carcinogenicity (Three-class) & Non-required & 0.6468 & Non-required & 0.4987 \\
\hline
\end{tabular}


Table 5

ADMET - Regression study

ADMET Predicted Profile -- Regression

\begin{tabular}{|c|c|c|c|c|}
\hline \multirow[b]{2}{*}{ Model } & \multicolumn{2}{|c|}{ Established Compound } & \multicolumn{2}{|c|}{$\begin{array}{l}\text { Virtual Screened } \\
\text { Compound }\end{array}$} \\
\hline & Value & Unit & Value & Unit \\
\hline \multicolumn{5}{|l|}{ Absorption } \\
\hline Aqueous solubility & -3.2214 & LogS & -2.7704 & LogS \\
\hline Caco-2 Permeability & 0.1928 & $\begin{array}{l}\text { LogPapp, } \\
\mathrm{cm} / \mathrm{s}\end{array}$ & 0.2113 & LogPapp, cm/s \\
\hline \multicolumn{5}{|l|}{ Distribution } \\
\hline \multicolumn{5}{|l|}{ Metabolism } \\
\hline \multicolumn{5}{|l|}{ Excretion } \\
\hline \multicolumn{5}{|l|}{ Toxicity } \\
\hline Rat Acute Toxicity & 2.778 & LD50, mol/kg & 2.6319 & LD50, mol/kg \\
\hline Fish Toxicity & 1.2483 & 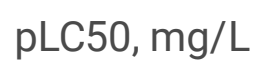 & 1.6451 & pLC50, mg/L \\
\hline $\begin{array}{l}\text { Tetrahymena Pyriformis } \\
\text { Toxicity }\end{array}$ & 0.6549 & $\mathrm{plGC50,ug/L}$ & 0.423 & pIGC50, ug/L \\
\hline
\end{tabular}

\subsection{Boiled EGG PLOT analysis}

Weak bioavailability and pharmacokinetics are results of failures in drug development, apart from ADMET, efficacy, and toxicity. Gastrointestinal consumption and brain access are the foremost two pharmacokinetic exercises central to appraisal at the numerous points of the drug discovery processes. Here, the Brain or IntestinaLEstimateD permeation method (BOILEDEgg) renders a specific forbidding model that estimates the physicochemical properties of small molecules i.e., polarity and lipophilicity [Table 6]. The investigation explicates that the established compound AEE788 (PubChem ID: 10297043) pitching inside the yellow ellipse (i.e. the yolk) exposes the possibility of a high BBB crossing. Whereas, the best Virtual screened compound holding a PubChem ID: 88265020 pitches inside the white ellipse signifying the possibility of huge intestinal absorption [Fig. 14]. Besides that, the plot value for a virtual screened compound with PubChem CID71313049almost overlaps with the established compound AEE-788. 
Table 6

Best 2 Established Docked compounds and Best 2 Virtual screened compounds used for Boiled Egg plot

\begin{tabular}{|lllllll|}
\hline Molecule & $\begin{array}{l}\text { PubChem } \\
\text { ID }\end{array}$ & $\begin{array}{l}\text { MW } \\
(\mathbf{g} / \mathbf{m o l})\end{array}$ & TPSA & MLOGP & $\begin{array}{l}\text { GI } \\
\text { absorption }\end{array}$ & $\begin{array}{l}\text { BBB } \\
\text { permeant }\end{array}$ \\
\hline AEE-788 & 10297043 & 440.58 & 60.08 & 3.22 & High & Yes \\
\hline Gefitinib & 123631 & 446.9 & 68.74 & 2.82 & High & Yes \\
\hline CID88265020 & 88265020 & 569.78 & 101.13 & 3.77 & High & No \\
\hline CID71313049 & 71313049 & 440.58 & 60.08 & 3.22 & High & Yes \\
\hline
\end{tabular}

\section{Methodology \\ 3.1 Selection of Inhibitors}

The selection of the inhibitors in the prevailing study is a wide search toward discovered inhibitors of VEGF was carried out through various literature studies. There were two types of inhibitors, type I inhibitors such as cediranib, vandetanib, semaxanib, pazopanib, targeting the

ATP binding site of kinase domain receptor of the VEFGR 2 while the type II inhibitor like sorafenib, tivozanib, and vatalanib target the extra binding site in kinase domain receptor of VEGFR 2 receptor. However,all the compounds that displayed a capable binding affinity to the protein structure and therefore inhibit its functionality were used for further investigation. 12 established compounds were identified with their unique PubChem ID and their 3D structure available in the database. Table 7 contains the list of all 12 established inhibitors of VEGF with their PubChem ID and other physicochemical properties. The 3D structures of the inhibitors were stored in 3D SDF format. 
Table 7

Established VEGF inhibitors with valid 3D structures stored in PubChem

\begin{tabular}{|llllllll|}
\hline $\begin{array}{l}\text { SL. } \\
\text { No. }\end{array}$ & Inhibitors & $\begin{array}{l}\text { Pubchem } \\
\text { ID }\end{array}$ & $\begin{array}{l}\text { Molecular } \\
\text { Weight }\end{array}$ & $\begin{array}{l}\text { H- } \\
\text { Bond } \\
\text { Donors }\end{array}$ & $\begin{array}{l}\text { H-Bond } \\
\text { Acceptors }\end{array}$ & $\begin{array}{l}\text { LogP } \\
\text { Value }\end{array}$ & Ref. \\
\hline 1 & Semaxanib & 5329098 & 238.29 & 2 & 1 & 2.5 & {$[10]$} \\
\hline 2 & Vandetanib & 3081361 & 475.362 & 1 & 7 & 4.9 & {$[11]$} \\
\hline 3 & Gefitinib & 123631 & 446.907 & 1 & 8 & 4.1 & {$[12]$} \\
\hline 4 & AEE788 & 10297043 & 440.595 & 2 & 5 & 4.6 & {$[13]$} \\
\hline 5 & Parp & 16760621 & 331.8 & 3 & 3 & - & {$[14]$} \\
\hline 6 & Pazopanib & 10113978 & 437.522 & 2 & 8 & 3.1 & {$[15]$} \\
\hline 7 & Nintedanib & 9809715 & 539.636 & 2 & 7 & 3.3 & {$[16]$} \\
\hline 8 & Cediranib & 9933475 & 450.514 & 1 & 7 & 4.9 & {$[17]$} \\
\hline 9 & Bevacizumab & 24801580 & 396.153 & 1 & 4 & - & {$[18]$} \\
\hline 10 & Sorafenib & 216239 & 464.829 & 3 & 7 & 4.1 & {$[19]$} \\
\hline 11 & Tivozanib & 9911830 & 454.867 & 2 & 7 & 4 & {$[20]$} \\
\hline 12 & Vatalanib & 151194 & 346.818 & 1 & 4 & 4.5 & {$[21-22]$} \\
\hline
\end{tabular}

Docking studies required a crystal structure of the VEGF protein which was taken from Protein

Data Bank (PDB) has a PDB ID: 3V2A [23] and stored for further additional processing to

perform the docking process. Additional ligand preparation was introduced along with 3D structures of the established compounds downloaded from the PubChem database was loaded in the LigPrep module of Schrodinger suite, 2013 (Schrodinger. LLC, New York, NY)[24-29]. The process optimization was performed using the OPLS 2005 force field algorithm to get all the compound structures in a single file [30-34]. The obtained file was stored in SDF format and applied for docking studies [35-40].

\subsection{Molecular Docking}

Molegro Virtual Docker (MVD), the software performs molecular docking and unified high potential Piece-Wise Linear Potential (PLP) and MolDock scoring function [41]. The crystal structures of the target protein were used for docking and the existing ligand was removed from the protein structure [42-47]. The first cavity was recorded to hold the bound ligand earlier to its elimination and was also observed to have the largest volume and was selected for the further procedure of docking with ligands [48-55]. The single SDF file containing all the 12 ligands created through the LigPrep module was loaded in the docker. Docking procedure parameter

was fixed at a maximum iteration of 1500 , grid solution 0.2 having a binding affinity, and

maximum population size 50[56-60]. The protein and ligands were appraised on the subsequent confirmation of the Internal Electrostatic interaction (Internal ES), sp2-sp2 torsions, and internal hydrogen bond interaction. A post dock study included energy minimization and $\mathrm{H}$ bond optimization. Simplex Evolution was fixed at max steps 300 and neighbor distance faster

1.00[59-65]. Nelder Mead Simplex Minimization (using non-grid force field and H-bond directionality) was applied after the docking to minimize the complex energy of ligand-receptor interaction [66-71]. 


\subsection{Virtual screening}

Molecular docking produced a re-rank score for every compound which is indicative of the interaction between the compounds with the target protein [61-62]. Compound with a lower rerank score indicates the effective affinity to the target protein and was confirmed to be the best-

established compound. A similarity searching of that compound was carried out for determining the best compound having a higher affinity different from any established

drugs[65-68]. Therefore, virtual screening was performed against the PubChem database generated by $\mathrm{NIH}$, one of the public chemical repositories which comprise 93 million chemical

compounds. The threshold was fixed at $>=95$ and filtration property parameters were

introduced by the component rule of Lipinski's rule of five. The compound structures were stored in SDF format and were promoted for the molecular docking procedure supported by the

same procedure against the crystal structure of the target protein VEGF to recognize the compound possessing exceeded affinity [67-68].

\subsection{Molecular Dynamics Simulation}

The MD simulation was performed on the Desmond module (Schrodinger) used for scrutinizing details of molecular motion as a function of time-based on the fact that a molecule in a three-

dimensional space has internal motion resulting in conformational change which plays an essential role in their function, this holds true for every biological interaction [24]. The Molecular

dynamic simulation of the virtual screened compound and best-established compound provides crucial information on geometrical and thermodynamical aspects of the compound.

For a moment TIP3P model and Gromos9643a1 force field were applied. The system was neutralized with counterions ( $\mathrm{NaCl}) 0.15 \mathrm{M}$. The cubic simple point charge (SPC) water box was applied, Box shape length, width, height is $10 \AA$ box volume $564112 \AA$. Two-step (NVT and NPT) energy minimization (50000 ps) till the minimization completion was continued. The ambient pressure was set at 1.013 bar and temperature $310 \mathrm{~K}$ for $150 \mathrm{~ns}$. The thermodynamic stability of the VEGF and ligands was analyzed using root means square fluctuations (RMSF) and root

means square deviation (RMSD). All the simulation was repeated three times with

approximately 1000 frames per simulation. The understanding of structural and functional behaviors of the compound is analyzed through a simulation diagram, wherein, RMSD, RMSF, protein-ligand interaction, and ligand properties are analyzed [69-73].

\subsection{Drug-Drug comparative study}

The unnamed complex structures were attained from the docking result of the established compounds and introduced in Molegro Virtual Docker. It was refined by eliminating all the ligands, constraints, and cavities without the protein structure. Subsequent results were

recorded to detect the best pose of the best-established compound and then it was

imported[66]. The structure produced as a consequence was rescued in PDB format.

Revaluation of parameters was directed and the data collected was kept in an excel sheet. Similarly, the complex structures were recaptured from the virtual screening result and the same method was iterated. An excel sheet was fixed to investigate all the affinities, hydrogen interaction, steric energy, and high re-rank score to recognize the best inhibitor [66-68].

\subsection{Pharmacophore studies}

Pharmacophore studies comprise different interaction types of ligand and receptor including $\mathrm{H}$ bond interaction, electrostatic interaction, hydrophobic interaction, and aromatic interaction. It

is performed by applying Accelrys Discovery Studio 3.5 DS Visualizer. The developed pharmacophore model included the excluded volume spheres, which imitate the inaccessible areas along with any potential ligand [66].

\subsection{Bioactivity and ADMET profiling of compound}

Every comparable compound was appraised for its Drug capability by applying Lipinski filter. ADMET represents the pharmacological activity of the compound, which was determined by applying the admetSAR database provides an effective interface to evaluate the biological and 
chemical profiles. The properties of the ADMET profile include adsorption, digestion, metabolism, excretion, and toxicity which perform major roles in the development and discovery of drugs [74]. The database comprises 5 quantitative regression models and 22 qualitative classifications which implement the result with high predictive precision. The appraisal of these properties was carried out using admetSAR

(http://Immd.ecust.edu.cn:8000/). The bio-activity properties and toxicity of the two compounds with the highest affinity from the docking and virtual screening studies were predicted using this online admetSARtool[74].

\subsection{Boiled-Egg Plot}

A Boiled Egg Plot uses the spontaneous and reproducible statistical plot to predict the 2 passive predictions: gastrointestinal (GI) absorption and brain penetration (BBB), which determines its propriety in the development and discovery of drugs. The Cartesian directions of both the ovals were followed to give the dependence data. Also, it contains a few parameters;

MW, TPSA, MLOGP, GI, and BBB to restructure the BOILED-Egg plot [75]. If in the plot, the compounds of our interest lie on the yellow ellipse, the possibility of the compound penetrating

the brain (BBB) is greater indicative of poor compound. Similarly, the compound's Gastrointestinal Absorption (GI) is high if it lies in the white region of the plot indicative of the compound with great absorption capacity [75-76]. Additionally, besides these two observations, if the compounds of our interest are placed on the grey area, excluding the yellow ellipse and white areas, and are out of range of the plot as well, the compounds are nonabsorptive and non-brain penetrative. As per the re-rank affinities, analysis of this plot was performed for the best two inhibitors from the first docking results and the best two compounds

obtained from the second docking studies i.e. virtual screening results [76]. All these four compounds were considered separately to assess parameters of Gastrointestinal Absorption (GI) and Blood-Brain Barrier (BBB).

\section{Conclusion}

Ovarian cancer is the common lethal gynecologic malignancy and notwithstanding many available drugs, this disease is still progressing day by day. Several established compounds which perform as angiogenesis inhibitors are previously identified but the strategy here was to recognize a compound that is more effective than the present drugs, hence, from literature survey all types of VEGFR 2 inhibitors were retrieved. The molecular docking results display the

strength of the compound with a PubChem ID: 88265020 to inhibit the VEGF protein. The dynamic simulation compared the conformational changes over a timestep of compound (PubChem ID: 88265020) with the best-established compound. The Electrostatic interaction of the best virtual screened compound and hydrophobic forces enclosing it with a large number of hydrogen-bonding interactions with the amino acid debris promotes productive pharmacophoric interplays. The boiled egg-plot investigation stipulates that the best virtual screened compound is located in the white area of the plot symbolizing peculiar intestinal absorption. The foregoing qualities decide that the best virtual screened drug is actively bioavailable. Therefore, the information suggests that the best virtual screened compound has an essential inhibitory effect against the target protein VEGF. Additionally, the aforementioned

investigation presents a field for the examination of the compound with PubChem ID:

88265020 to be investigated for the prevention of ovarian cancer. It indicates a compound with

a PubChem ID: 88265020 inhibits VEGF more strongly than the established drug AEE788. Moreover, In vitro study might acknowledge the aforementioned drug as a hopeful chapter in ovarian carcinoma.

\section{Declarations}

\section{Funding/Acknowledgment}

1. This work was supported by the Taif University Researchers Supporting Program (Project number: TURSP-2020/151), Taif University, Saudi Arabia. 
2. The authors are grateful to the Deanship of Scientific Research, King Saud University for funding through Vice Deanship of Scientific Research Chairs.

3. SKS thank Alagappa University, Department of Biotechnology (DBT), New Delhi (No. BT/PR8138/BID/7/458/2013, dated 23rd May, 2013), DST-PURSE $2^{\text {nd }}$ Phase Programme Order No. SR/PURSE Phase 2/38 (G dated 21.02.2017 and FIST (SR/FST/LSI - 667/2016),

MHRD RUSA 1.0 and RUSA 2.0 for providing the financial assistance. UP gratefully acknowledge Indian Council of Medical Research (ISRM/11/(19)/2017, dated: 09.08.2018).

4. SKS thankfully acknowledges the Tamil Nadu State Council for Higher Education (TANSCHE) for the research grant (Au/S.o. (P\&D): TANSCHE Projects: 117/2021).

\section{AUTHOR CONTRIBUTIONS}

SM contributed equally to this work with MA.SM, MA and was involved in Molecular docking, Molecular Dynamics Simulation, Writing - review \& editing. LP, AP, AC and MM were contributed towards Inhibitors collection, Datacuration, Formal analysis, Validation, Visualization.AB was involved in Molecular dynamic simulation. MY, RK, AAB and TH were involved in Molecular Docking, ADMET analysis, R Programming analysis, Writing - review \& editing. AN, AAB, TH and SKS were contributed in investigation, supervision, writing - review \& editing

\section{Conflicts of interest/Competing interests:}

The authors declare that they have no conflict of interest.

AVAILABILITY OF DATA AND MATERIALS:

Not applicable.

Code Availability:

Code will be provided as per the request

ETHICS APPROVAL AND CONSENT TO PARTICIPATE:

Not applicable.

HUMAN AND ANIMAL RIGHTS:

No animals/humans were used in the studies that are the basis of this research.

\section{References}

1. Tew WP (2016) "Ovarian cancer in the older woman."JGeriatr Oncol7(5):354-361

2. Tiper IV et al (2016) "VEGF potentiates GD3-mediated immune suppression by human ovarian cancer cells."Clinical Cancer Research: clincanres. 2518.2015.

3. Weiderpass E, Tyczynski JE (2015) "Epidemiology of patients with ovarian cancer with and without a BRCA1/2 Mutation."Molecular diagnosis \& therapy19(6):351-364 
4. Premalata C et al (2016) "Expression of VEGF-A in Epithelial Ovarian Cancer: Correlation with Morphologic Types, Grade and Clinical Stage."The Gulf journal of oncology1(21):4954

5. Horikawa $\mathrm{N}$ et al (2017) "Expression of vascular endothelial growth factor in ovarian cancer inhibits tumor immunity through the accumulation of myeloid-derived suppressor cells."Clinical Cancer Research23(2):587-599

6. Tino AB et al (2016) "Resveratrol and acetyl-resveratrol modulate activity of VEGF and IL-8 in ovarian cancer cell aggregates via attenuation of the NF-KBprotein."Journal of ovarian research9(1):84

7. Grunewald T, Ledermann JA (2017) "Targeted Ther ovarian cancer "Best Pract Res Clin Obstet Gynecol 41:139-152

8. Huang L, Huang Z, Bai Z, Xie R, Sun L, Lin K (2012) Development and strategies of VEGFR2/KDR inhibitors. Future Med Chem 4(14):1839-1852

9. Traxler P, Allegrini PR, Brandt R et al (2004) AEE788: a dual family epidermal growth factor receptor/ErbB2 and vascular endothelial growth factor receptor tyrosine kinase inhibitor with antitumor and antiangiogenic activity. Cancer Res 64(14):4931-4941

10. Choi H-J et al (2015) "Anti-vascular therapies in ovarian cancer: moving beyond anti-VEGF approaches."Cancer and Metastasis Reviews34(1):19-40

11. Belotti D et al (2003) "Matrix metalloproteinases (MMP9 and MMP2) induce the release of vascular endothelial growth factor (VEGF) by ovarian carcinoma cells: implications for ascites formation."Cancer Res63(17):5224-5229

12. Wedge SR et al (2002) "ZD6474 inhibits vascular endothelial growth factor signaling, angiogenesis, and tumor growth following oral administration."Cancer Res62(16):46454655

13. Ciardiello F et al (2001) "Inhibition of growth factor production and angiogenesis in human cancer cells by ZD1839 (Iressa), a selective epidermal growth factor receptor tyrosine kinase inhibitor."Clinical Cancer Research7(5):1459-1465

14. Traxler P et al (2004) "AEE788: a dual family epidermal growth factor receptor/ErbB2 and vascular endothelial growth factor receptor tyrosine kinase inhibitor with antitumor and antiangiogenic activity."Cancer Res64(14):4931-4941

15. Liu J et al (2018) "Assessment and management of diarrhea following VEGF receptor TKI treatment in patients with ovarian cancer."Gynecologic oncology

16. Richardson DL et al (2018) "Paclitaxel with and without pazopanib for persistent or recurrent ovarian cancer: a randomized clinical trial."JAMA oncology4(2):196-202

17. Khalique S, Banerjee S (2017) "Nintedanib in ovarian cancer."Expert opinion on investigational drugs26(9):1073-1081

18. Orbegoso C et al (2017) "The role of Cediranib in ovarian cancer."Expert opinion on pharmacotherapy18(15):1637-1648 
19. Zhang W et al (2017) "The benefits and side effects of bevacizumab for the treatment of recurrent ovarian cancer."Current drug targets18(10):1125-1131

20. Azad NS et al (2008) "Combination targeted therapy with sorafenib and bevacizumab results in enhanced toxicity and antitumor activity. "Journal of Clinical Oncology

$$
\text { 26(22):3709-3714 }
$$

21. Nakamura $\mathrm{K}$ et al (2006) "KRN951, a highly potent inhibitor of vascular endothelial growth factor receptor tyrosine kinases, has antitumor activities and affects functional vascular properties."Cancer Res66(18):9134-9142

22. Xu L et al (2000) "Inhibition of malignant ascites and growth of human ovarian carcinoma by oral administration of a potent inhibitor of the vascular endothelial growth factor receptor tyrosine kinases. "International J Oncol 16(3):445-499

23. Brozzo MS et al (2012) "Thermodynamic and structural description of allosterically regulated VEGFR-2 dimerization."Blood119(7):1781-1788

24. Schrodinger LLC (2009) NY, USA,

25. LigPrep, Schrodinger LLC Ney York, NY

26. Prime S LLC, Ney York, NY

27. Protein P, Wizard Schrodinger, LLC, Ney York, NY

28. Qikprop S LLC, Ney York, NY

29. Sharma K, Patidar K, Ali MA, Patil P, Goud H, Hussain T, Nayarisseri A, Singh SK (2018) Structure-based virtual screening for the identification of high affinity compounds as potent VEGFR2 inhibitors for the treatment of renal cell carcinoma. Curr Top Med Chem 18(25):2174-2185

30. Sahila MM, Babitha PP, Bandaru S, Nayarisseri A, Doss VA (2015) Molecular docking based screening of GABA (A) receptor inhibitors from plant derivatives. Bioinformation 11(6):280

31. Vuree S, Dunna NR, Khan IA, Alharbi KK, Vishnupriya S, Soni D, Shah P, Chandok H, Yadav $M$, Nayarisseri A (2013) Pharmacogenomics of drug resistance in Breast Cancer Resistance Protein (BCRP) and its mutated variants. J Pharm Res 6(7):791-798

32. Monteiro AFM, Viana JDO, Nayarisseri A, Zondegoumba EN, Mendonça Junior FJB, Scotti MT, Scotti L (2018) Computational studies applied to flavonoids against alzheimer's and parkinson's diseases. Oxidative medicine and cellular longevity, 2018

33. Bandaru S, GangadharanSumithnath T, Sharda S, Lakhotia S, Sharma A, Jain A, Hussain T, Nayarisseri A, Singh K, S (2017) Helix-Coil transition signatures B-Raf V600E mutation and virtual screening for inhibitors directed against mutant B-Raf. Curr Drug Metab 18(6):527534

34. Kelotra A, Gokhale SM, Kelotra S, Mukadam V, Nagwanshi K, Bandaru S, Nayarisseri A, Bidwai A (2014) Alkyloxy carbonyl modified hexapeptides as a high affinity compounds for Wnt5A protein in the treatment of psoriasis. Bioinformation 10(12):743 
35. Basak SC, Nayarisseri A, González-Díaz H, Bonchev D (2016) Editorial (Thematic Issue: chemoinformatics models for pharmaceutical design, part 1). 22(33):5041-5042

36. Basak SC, Nayarisseri A, González-Díaz H, Bonchev D (2016) Editorial (Thematic Issue: Chemoinformatics models for pharmaceutical design, part 2). 22(34):5177-5178

37. Prajapati L, Khandelwal R, Yogalakshmi KN, Munshi A, Nayarisseri A (2020) Computeraided Structure prediction of Bluetongue Virus coat protein VP2 assisted by Optimized

Potential for Liquid Simulations (OPLS). Curr Top Med Chem 20(19):1720-1732

38. Nayarisseri A, Khandelwal R, Madhavi M, Selvaraj C, Panwar U, Sharma K, Hussain T, Singh SK (2020) Shape-based machine learning models for the potential novel COVID-19 protease inhibitors assisted by molecular dynamics simulation. Curr Top Med Chem

$$
\text { 20(24):2146-2167 }
$$

39. Nayarisseri A (2020) Most Promising Compounds for Treating COVID-19 and Recent Trends in Antimicrobial \& Antifungal Agents. Curr Top Med Chem 20(24):2119-2125

40. Pochetti G, Mitro N, Lavecchia A, Gilardi F, Besker N, Scotti E, Aschi M, Re N, Fracchiolla G, Laghezza A, Tortorella P (2010) Structural insight into peroxisome proliferator-activated receptor $y$ binding of two ureidofibrate-like enantiomers by molecular dynamics, cofactor interaction analysis, and site-directed mutagenesis. J Med Chem 53(11):4354-4366

41. Bitencourt-Ferreira G, Azevedo WFD (2019) Molegro virtual docker for docking. Docking screens for drug discovery. Humana, New York, NY, pp 149-167

42. Natchimuthu V, Bandaru S, Nayarisseri A, Ravi S (2016) Design, synthesis and computational evaluation of a novel intermediate salt of N-cyclohexyl-N-

(cyclohexylcarbamoyl)-4-(trifluoromethyl) benzamide as potential potassium channel blocker in epileptic paroxysmal seizures. Comput Biol Chem 64:64-73

43. Bandaru S, Alvala M, Akka J, Sagurthi SR, Nayarisseri A, Kumar Singh S, Mundluru P, H (2016) Identification of small molecule as a high affinity $\beta 2$ agonist promiscuously targeting wild and mutated (Thr164lle) $\beta 2$ adrenergic receptor in the treatment of bronchial asthma. Curr Pharm Design 22(34):5221-5233

44. Majhi M, Ali MA, Limaye A, Sinha K, Bairagi P, Chouksey M, Shukla R, Kanwar N, Hussain T, Nayarisseri A, Singh SK (2018) An in silico investigation of potential EGFR inhibitors for the clinical treatment of colorectal cancer. Curr Top Med Chem 18(27):2355-2366

45. Khandelwal R, Chauhan AP, Bilawat S, Gandhe A, Hussain T, Hood EA, Nayarisseri A, Singh SK (2018) Structure-based virtual screening for the identification of high-affinity small molecule towards STAT3 for the clinical treatment of osteosarcoma. Curr Top Med Chem 18(29):2511-2526

46. Sinha K, Majhi M, Thakur G, Patidar K, Sweta J, Hussain T, Nayarisseri A, Singh SK (2018) Computer-aided drug designing for the identification of high-affinity small molecule targeting cd20 for the clinical treatment of chronic lymphocytic leukemia (CLL). Curr Top Med Chem 18(29):2527-2542 
47. Chandrakar B, Jain A, Roy S, Gutlapalli VR, Saraf S, Suppahia A, Verma A, Tiwari A, Yadav M, Nayarisseri A (2013) Molecular modeling of Acetyl-CoA carboxylase (ACC) from Jatropha curcas and virtual screening for identification of inhibitors. J Pharm Res 6(9):913-918

48. Nayarisseri A, Moghni SM, Yadav M, Kharate J, Sharma P, Chandok KH, Shah KP (2013) In silico investigations on HSP90 and its inhibition for the therapeutic prevention of breast cancer. J Pharm Res 7(2):150-156

49. Udhwani T, Mukherjee S, Sharma K, Sweta J, Khandekar N, Nayarisseri A, Singh SK (2019) Design of PD-L1 inhibitors for lung cancer. Bioinformation 15(2):139

50. Shukla P, Khandelwal R, Sharma D, Dhar A, Nayarisseri A, Singh SK (2019) Virtual screening of IL-6 inhibitors for idiopathic arthritis. Bioinformation 15(2):121

51. Nayarisseri A, Hood EA (2018) Advancement in microbial cheminformatics. Curr Top Med Chem 18(29):2459-2461

52. Jain D, Udhwani T, Sharma S, Gandhe A, Reddy PB, Nayarisseri A, Singh SK (2019) Design of novel JAK3 Inhibitors towards Rheumatoid Arthritis using molecular docking analysis. Bioinformation 15(2):68

53. Nayarisseri A, Singh SK (2019) Functional inhibition of VEGF and EGFR suppressors in cancer treatment. Curr Top Med Chem 19(3):178-179

54. Gokhale P, Chauhan APS, Arora A, Khandekar N, Nayarisseri A, Singh SK (2019) FLT3 inhibitor design using molecular docking based virtual screening for acute myeloid leukemia. Bioinformation 15(2):104

55. Ali MA, Vuree S, Goud H, Hussain T, Nayarisseri A, Singh SK (2019) Identification of highaffinity small molecules targeting gamma secretase for the treatment of Alzheimer's disease. Curr Top Med Chem 19(13):1173-1187

56. Patidar K, Panwar U, Vuree S, Sweta J, Sandhu MK, Nayarisseri A, Singh SK (2019) An in silico approach to identify high affinity small molecule targeting m-TOR inhibitors for the clinical treatment of breast cancer. Asian Pac J cancer prevention: APJCP 20(4):1229

57. Pandey N, Yadav M, Nayarisseri A, Ojha M, Prajapati J, Gupta S (2013) Cross evaluation of different classes of alpha-adrenergic receptor antagonists to identify overlapping pharmacophoric requirements. J Pharm Res 6(1):173-178

58. Marunnan SM, Pulikkal BP, Jabamalairaj A, Bandaru S, Yadav M, Nayarisseri A, Doss VA (2017) Development of MLR and SVM aided QSAR models to identify common SAR of GABA uptake herbal inhibitors used in the treatment of Schizophrenia. Curr Neuropharmacol 15(8):1085-1092

59. Sweta, J., Khandelwal, R., Srinitha, S., Pancholi, R., Adhikary, R., Ali, M. A., ...Singh, S. K. (2019). Identification of high-affinity small molecule targeting IDH2 for the clinical treatment of acute myeloid leukemia. Asian Pacific journal of cancer prevention: APJCP, 20(8), 2287 
60. Nayarisseri A (2019) Prospects of utilizing computational techniques for the treatment of human diseases. Curr Top Med Chem 19(13):1071-1074

61. Sharda, S., Khandelwal, R., Adhikary, R., Sharma, D., Majhi, M., Hussain, T., ... Singh,S. K. (2019). A Computer-Aided Drug Designing for Pharmacological Inhibition of Mutant ALK for the Treatment of Non-small Cell Lung Cancer. Current topics in medicinal chemistry,19(13), 1129-1144

62. Limaye A, Sweta J, Madhavi M, Mudgal U, Mukherjee S, Sharma S, Hussain T, Nayarisseri A, Singh SK (2019) In silico insights on gd2: a potential target for pediatric neuroblastoma. Curr Top Med Chem 19(30):2766-2781

63. Nayarisseri A, Yadav M (2015) Editorial (Thematic Issue: Mechanistics in drug designexperimental molecular biology vs. molecular modeling). Curr Top Med Chem 15(1):3-4

64. Adhikary R, Khandelwal R, Hussain T, Nayarisseri A, Singh SK (2020) May Structural Insights into the Molecular Design of ROS1 Inhibitor for the Treatment of Non-Small Cell Lung Cancer (NSCLC). Current Computer-aided Drug Design. DOI: $10.2174 / 1573409916666200504105249$

65. Aher A, Udhwani T, Khandelwal R, Limaye A, Hussain T, Nayarisseri A, Singh SK (2020) In silico insights on IL-6: A potential target for multicentric castleman disease. Curr ComputAided Drug Design 16(5):641-653

66. Qureshi S, Khandelwal R, Madhavi M et al (2021 Jan) A Multi-Target Drug Designing for BTK, MMP9, Proteasome And TAK1 for the clinical treatment of Mantle Cell Lymphoma.

Curr Top Med Chem. DOI: 10.2174/1568026621666210119112336

67. Yadav, M., Khandelwal, R., Mudgal, U., Srinitha, S., Khandekar, N., Nayarisseri, A.,... Singh, S. K. (2019). Identification of Potent VEGF Inhibitors for the Clinical Treatment of Glioblastoma, A Virtual Screening Approach. Asian Pacific journal of cancer prevention:APJCP, 20(9), 2681

68. Nayarisseri A, Khandelwal R, Tanwar P, Madhavi M, Sharma D, Thakur G, Speck-Planche A, Singh SK (2021) Artificial Intelligence, Big data and Machine Learning approaches in Precision Medicine \& Drug Discovery. Curr Drug Targets. Jan 4. doi:

10.2174/1389450122999210104205732. Epub ahead of print. PMID: 33397265

69. Blessy JJ, Sharmila DJS (2015) Molecular simulation of N-acetylneuraminic acid analogs and molecular dynamics studies of cholera toxin-Neu5Gc complex. J Biomol Struct Dynamics 33(5):1126-1139

70. Wakui N, Yoshino R, Yasuo N, Ohue M, Sekijima M (2018) Exploring the selectivity of inhibitor complexes with Bcl-2 and Bcl-XL: A molecular dynamics simulation approach. J Mol Graph Model 79:166-174

71. Zhang, J., Scott, W. R., Gabel, F., Wu, M., Desmond, R., Bae, J., ... Straus, S. K.(2017). On the quest for the elusive mechanism of action of daptomycin: Binding, fusion, and 
oligomerization. Biochimica et Biophysica Acta (BBA)-Proteins and Proteomics, 1865(11), 1490-1499

72. Alhadrami, H. A., Sayed, A. M., Melebari, S. A., Khogeer, A. A., Abdulaal, W. H.,Al-Fageeh, M. B., ... Rateb, M. E. (2021). Targeting allosteric sites of human aromatase:A comprehensive in-silico and in-vitro workflow to find potential plant-based anti-breast cancer therapeutics. Journal of enzyme inhibition and medicinal chemistry, 36(1), 1334-1345

73. Rasul HO, Aziz BK, Ghafour DD, Kivrak A (2022) In silico molecular docking and dynamic simulation of eugenol compounds against breast cancer. J Mol Model 28(1):1-18

74. Cheng F, Li W, Zhou Y, Shen J, Wu Z, Liu G, Lee PW, Tang Y (2012) "admetSAR: a comprehensive source and free tool for assessment of chemical ADMET properties." :3099-3105

75. Daina A, Zoete V (2016) A boiled-egg to predict gastrointestinal absorption and brain penetration of small molecules. ChemMedChem 11(11):1117-1121

76. Daina A, Michielin O, Zoete V (2017) SwissADME: a free web tool to evaluate pharmacokinetics, drug-likeness and medicinal chemistry friendliness of small molecules.

Sci Rep 7(1):1-13

\section{Figures}




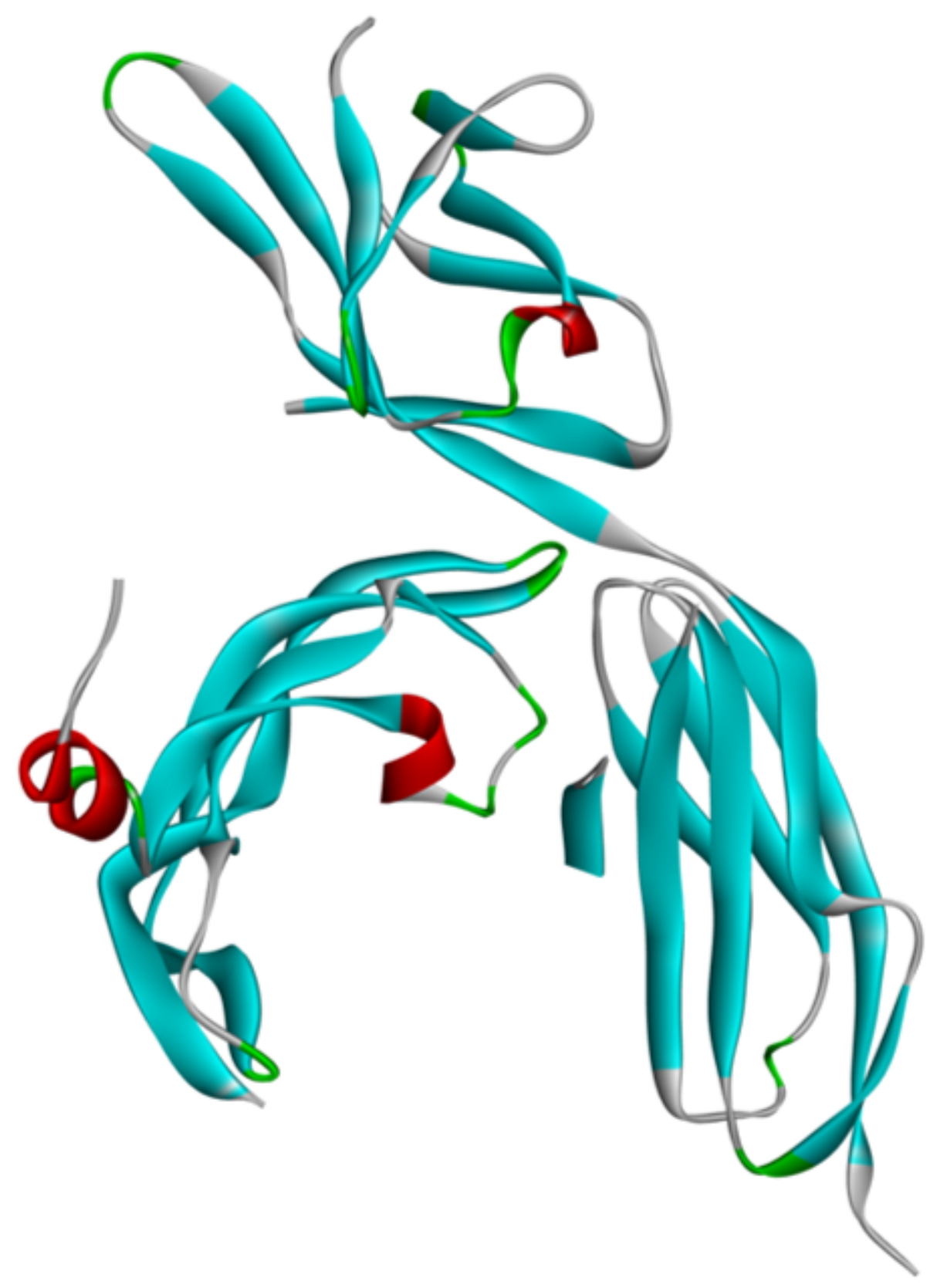

Figure 1 


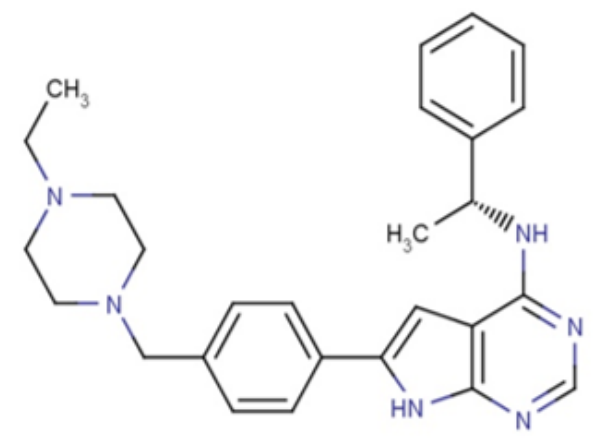

(i)

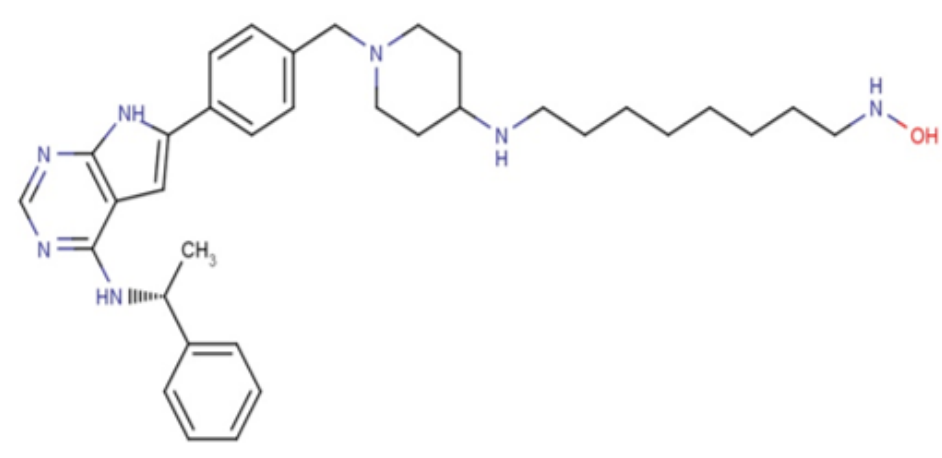

(II)

Figure 2

(I): PubChem ID: 10297043, the most established compound obtained from Molecular docking. (II): PubChem ID: 88265020, the most virtual screened compound obtained from Virtual Screening. 

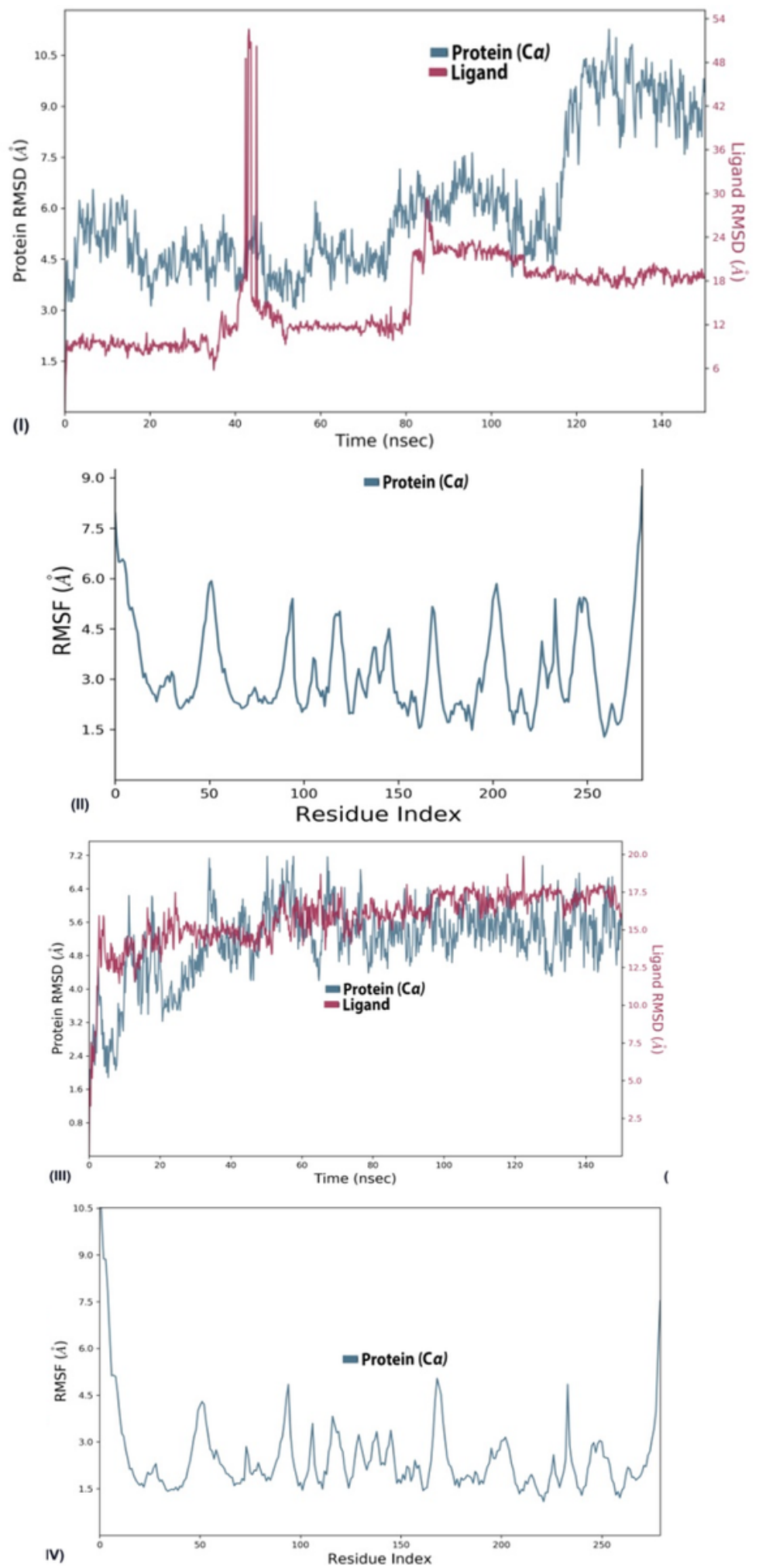

Figure 3

Molecular dynamics RMSD and RMSF of free VEGF (I,I); VEGFR complex with best established compound (PubChem CID: 10297043) (III,IV); VEGF complex with the best virtual screened compound (PubChem CID: 88265020) 


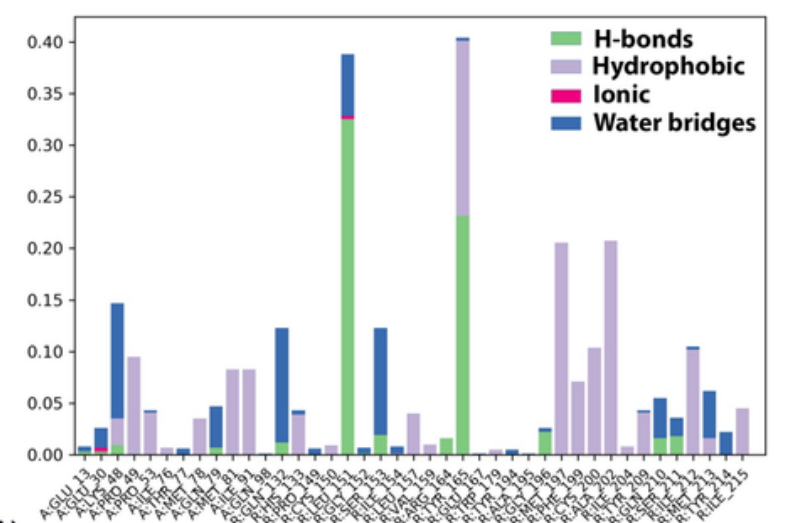

(A)
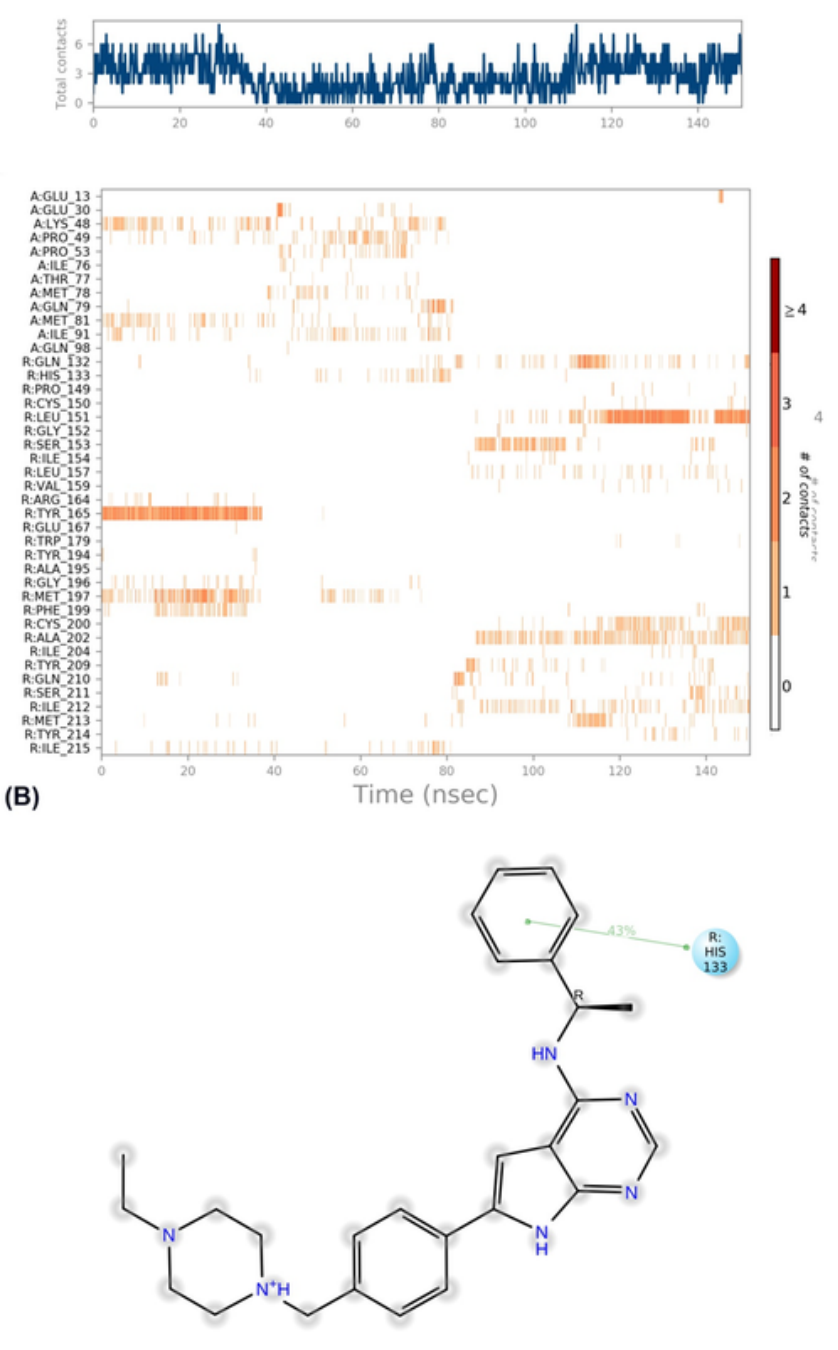

C

Figure 4

Interaction diagram of VEGF complex with best established compound PubChem CID: 10297043 observed during the molecular dynamics simulation. (A) The protein-ligand interaction diagram. (B) The residues that interact with the ligand in each trajectory frame. (C) Schematic diagram of ligand interaction with the amino acid residues of protein during MD simulation. 

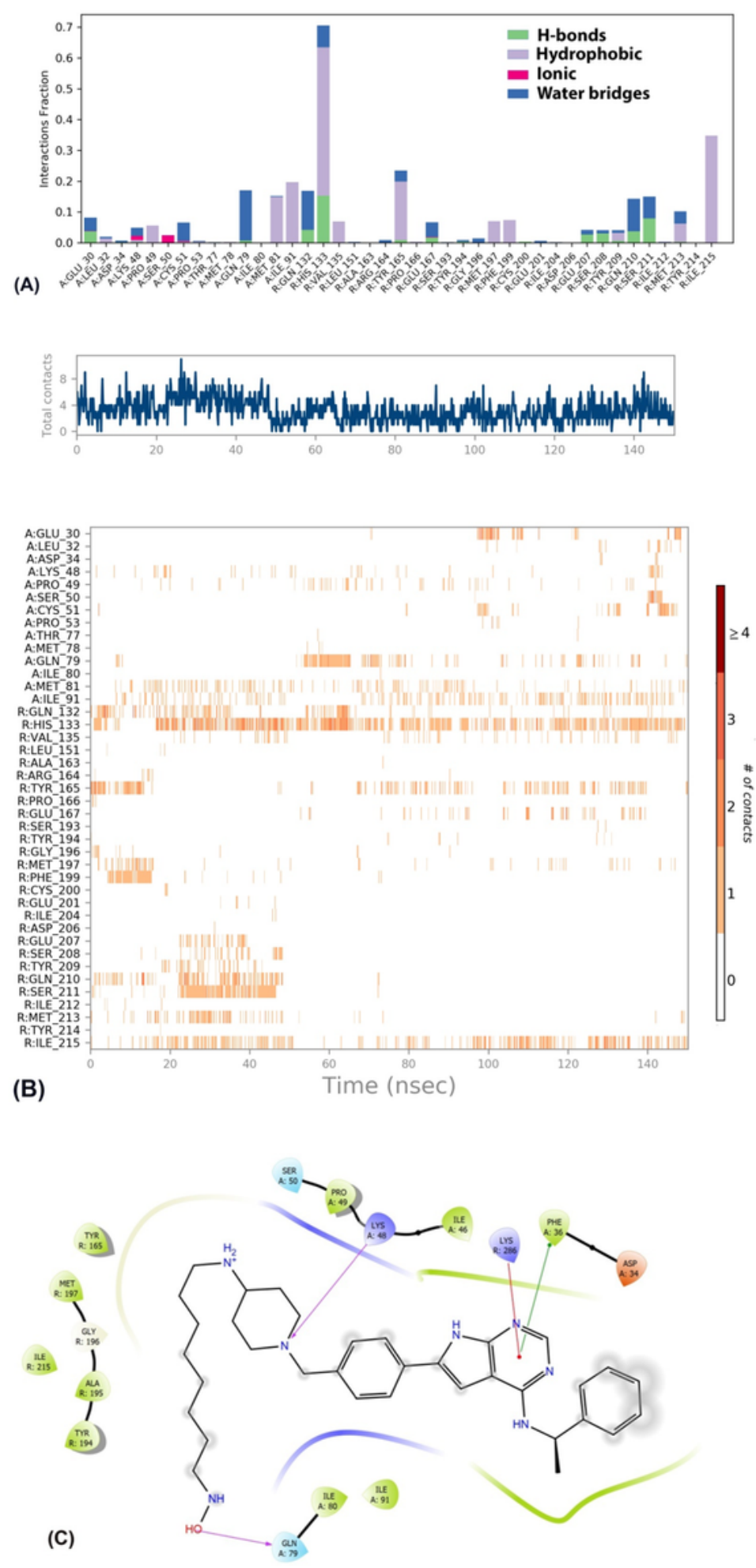

Figure 5

Interaction diagram of VEGF complex with best virtual screened compound (PubChem CID: 88265020 ) observed during the molecular dynamics simulation. (A) The protein-ligand interaction diagram. (B) The residues that interact with the ligand in each trajectory frame. (C) Schematic diagram of ligand interaction with the amino acid residues of protein during MD simulation. 

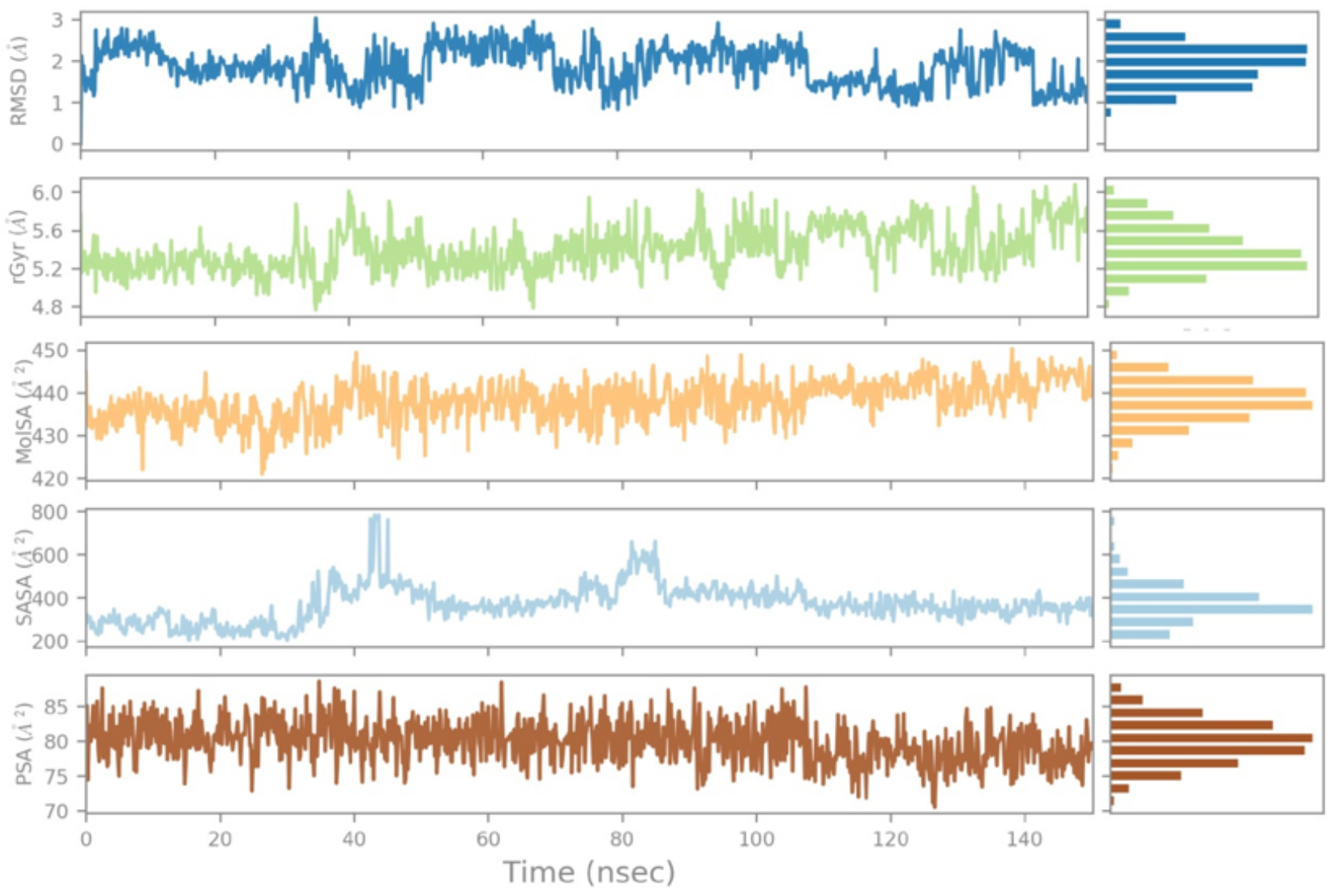

Figure 6

The ligand property trajectory of the VEGF complex with best established compound PubChem CID: 10297043during the 150 ns simulation. 

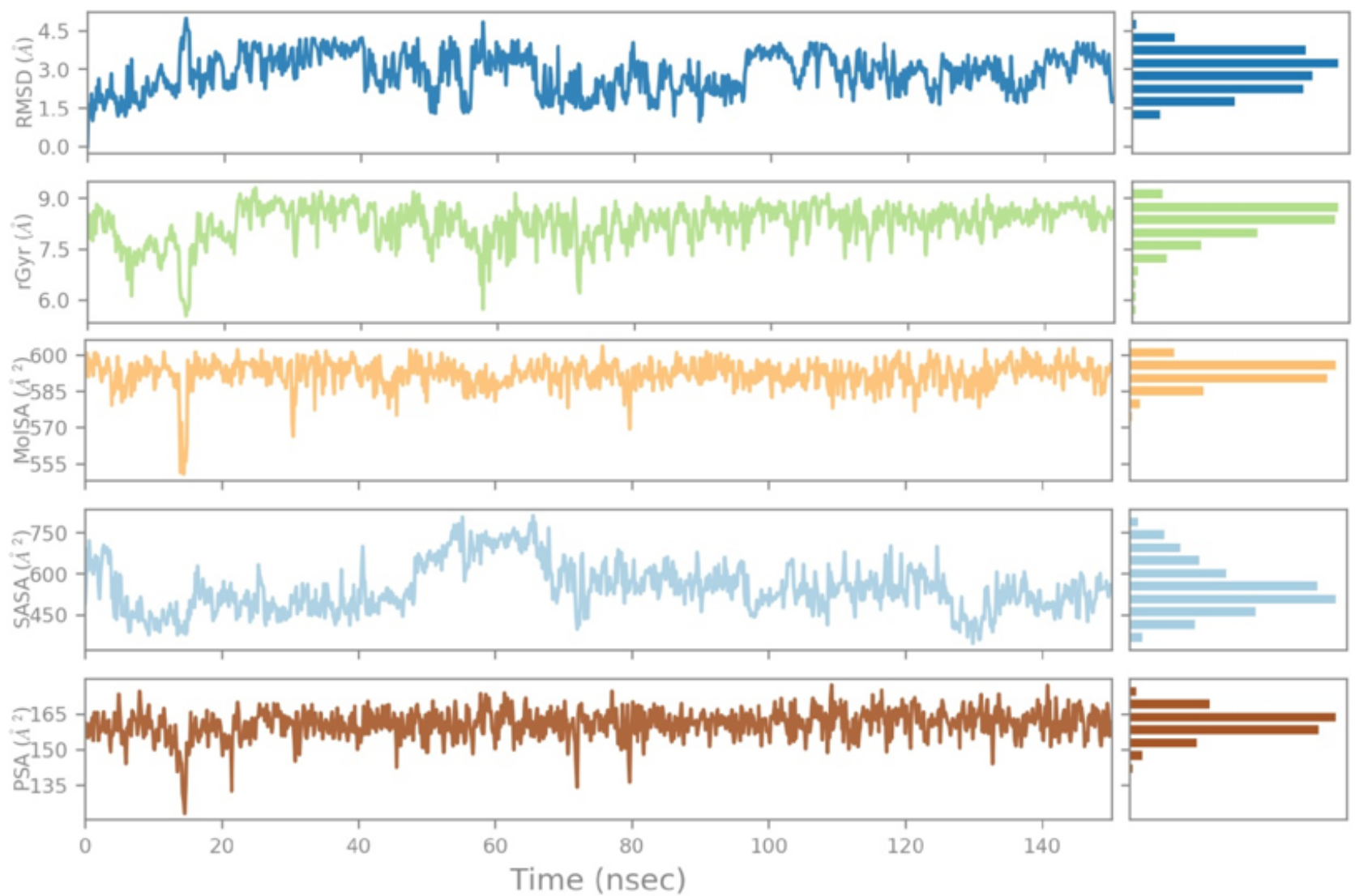

Figure 7

The ligand property trajectory of the VEGF complex with best virtual screened compound PubChem CID: 88265020 during the 150 ns simulation. 


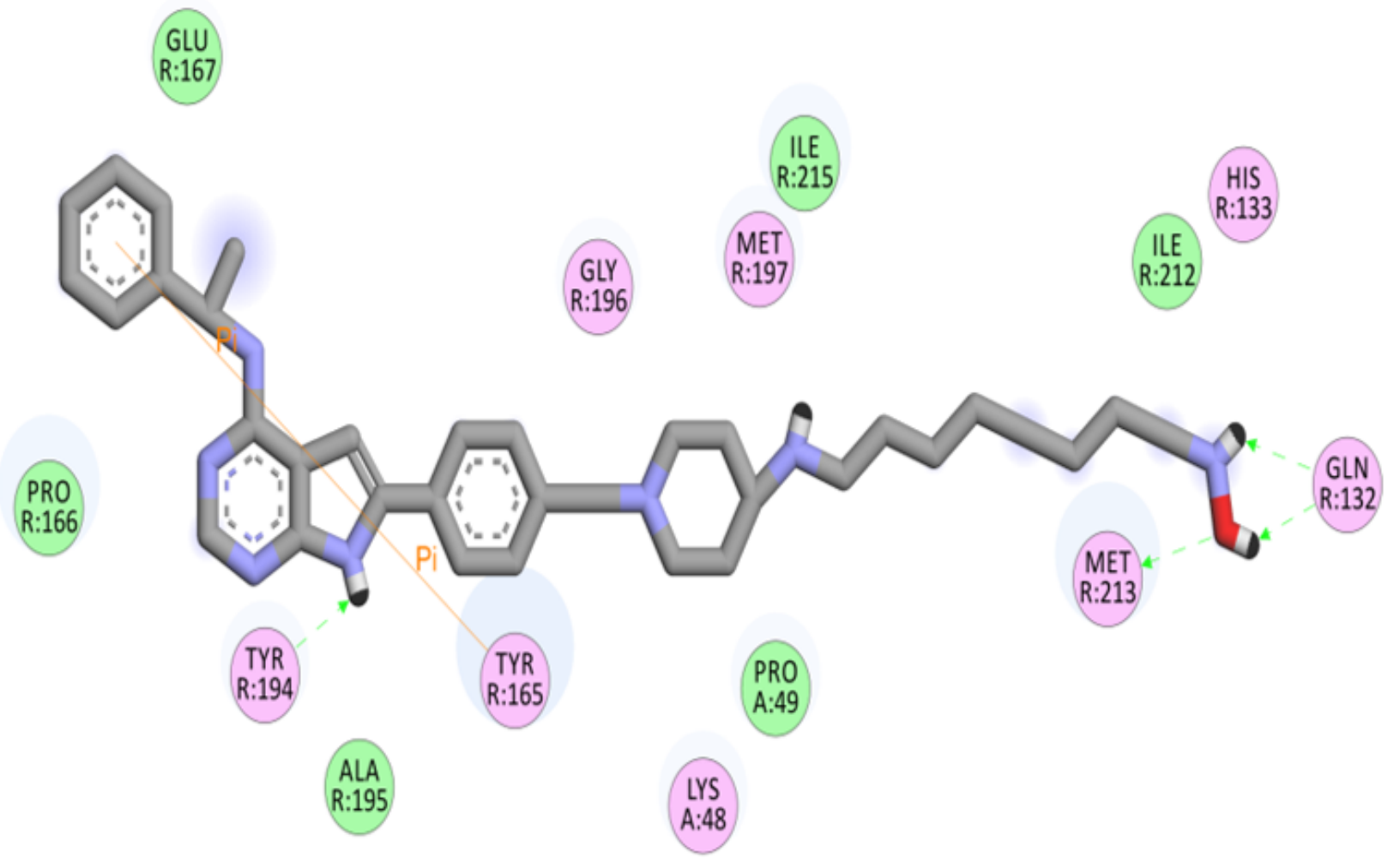

Figure 8

The most effective Virtual Screened compound (PubChem ID: 88265020), binding with VEGF shows Van der Waals interaction

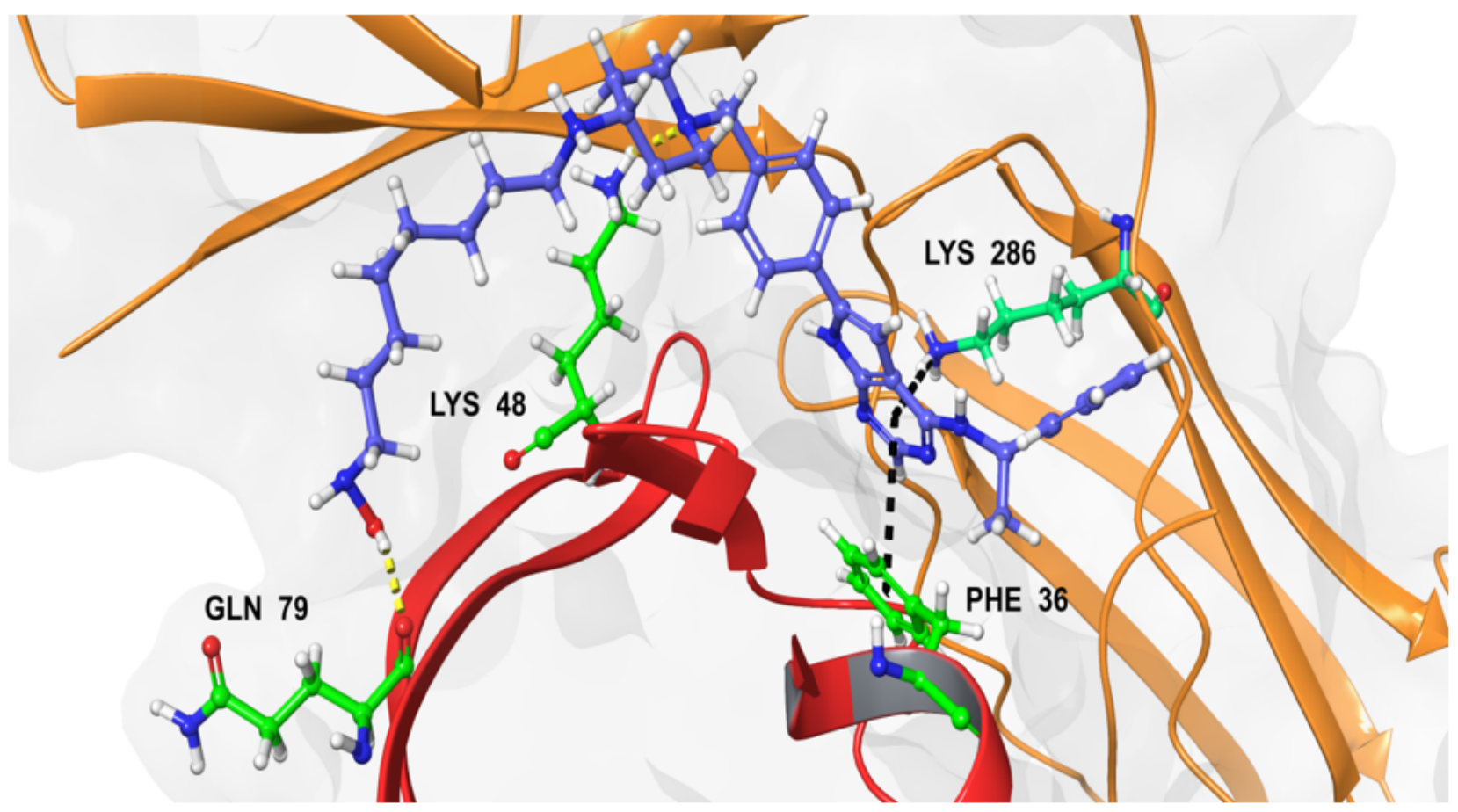

Figure 9 

shows Hydrogen Bond interaction

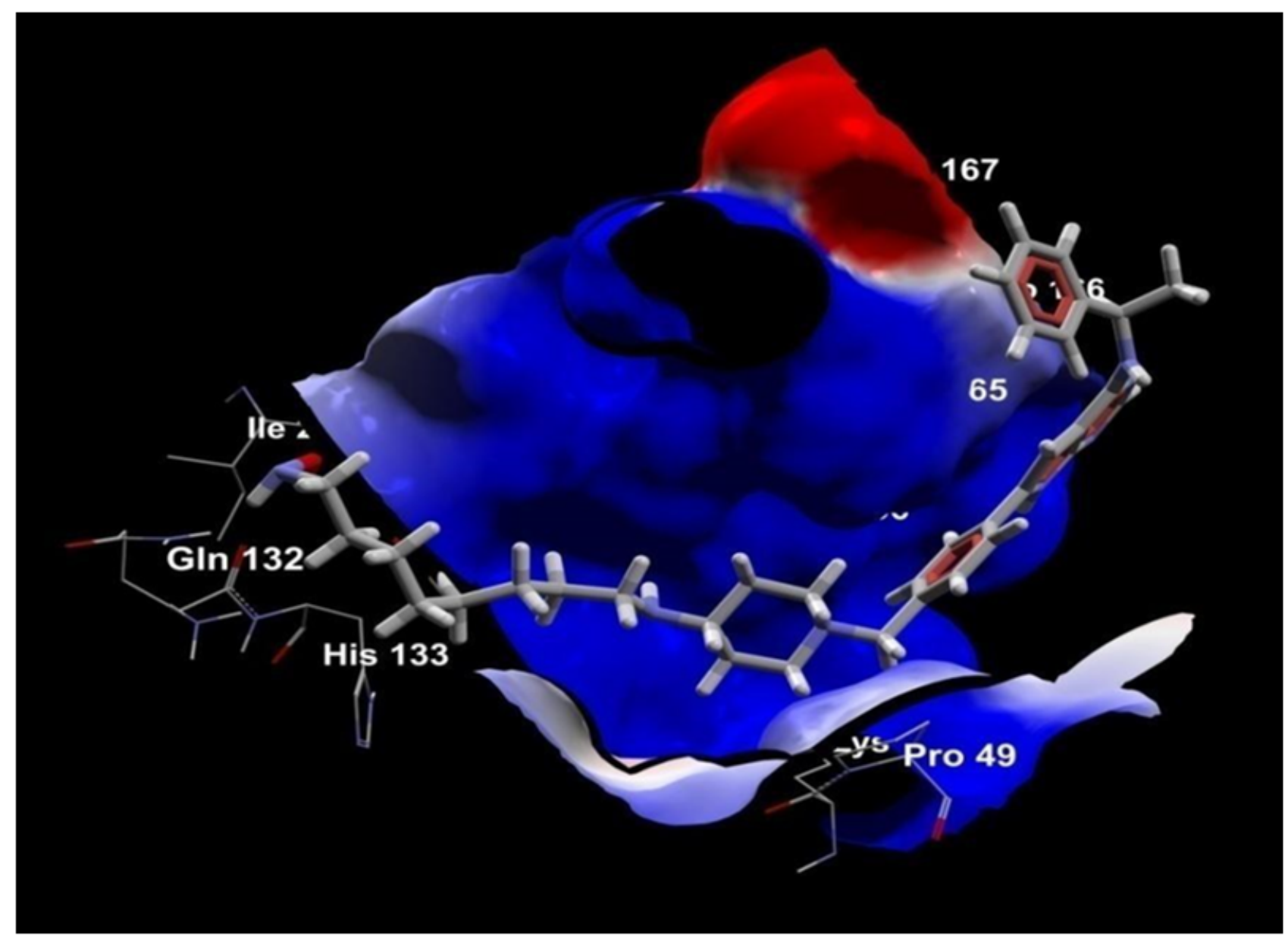

Figure 10

The most effective Virtual Screened compound (Pubchem ID: 88265020), binding with VEGF shows Electrostatic interaction 


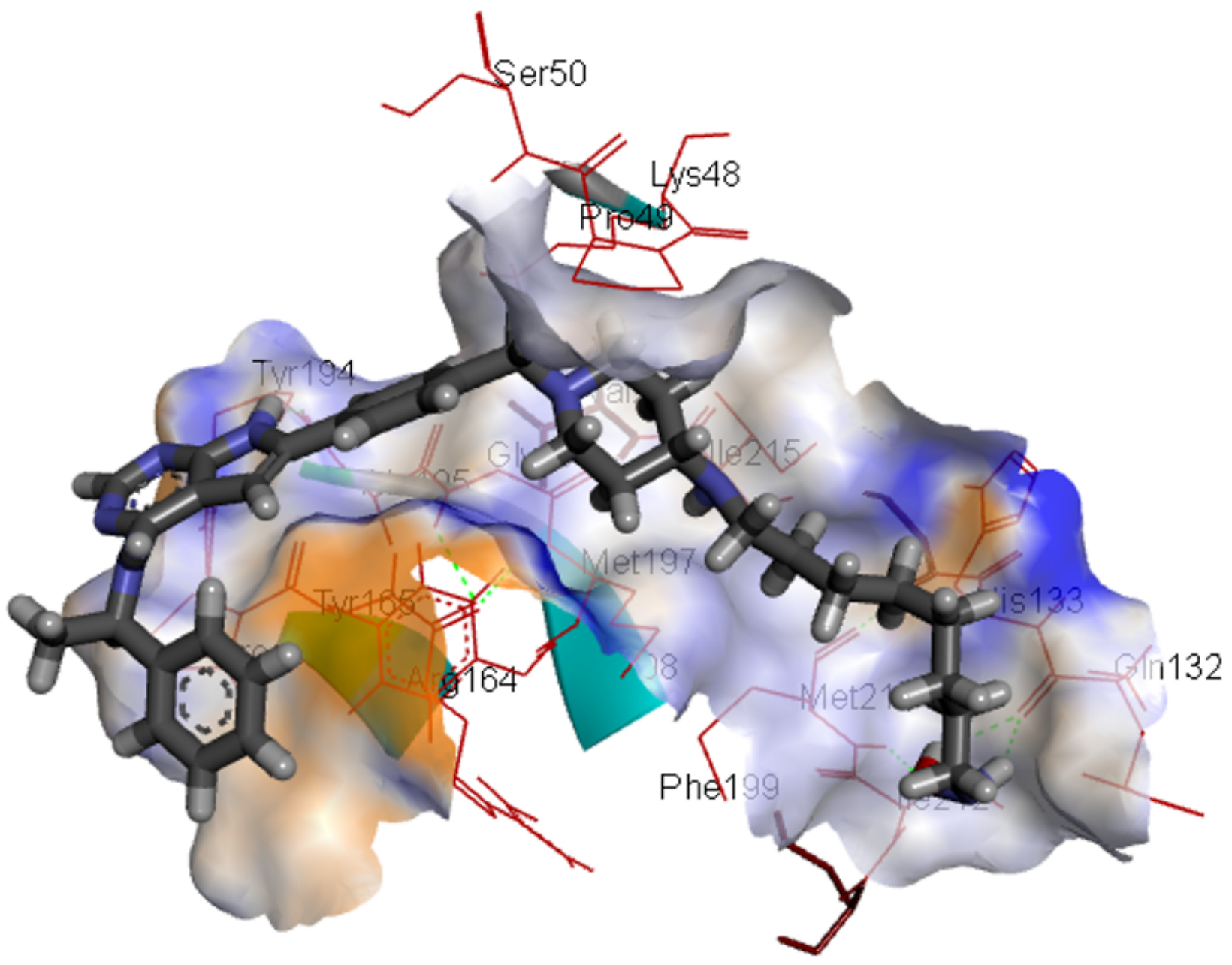

Figure 11

The most effective Virtual Screened compound (Pubchem ID: 88265020), binding with VEGF shows aromatic interaction 
his PC
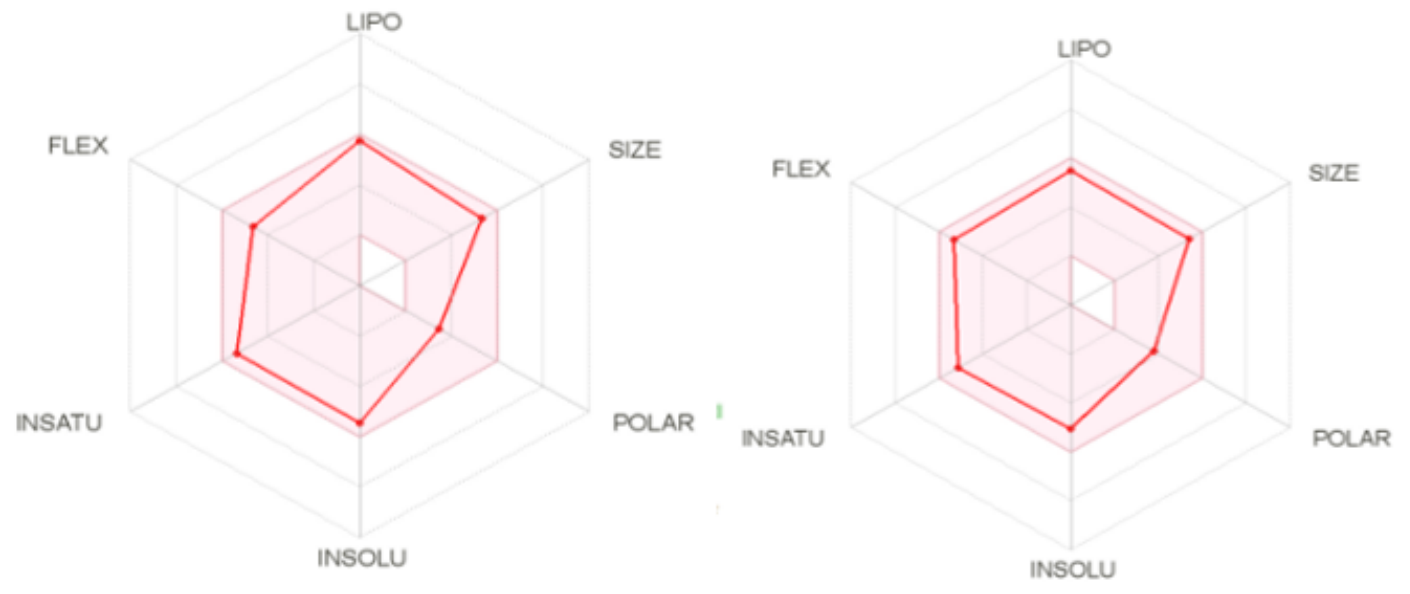

(i) AEE788

(ii) Gefitinib

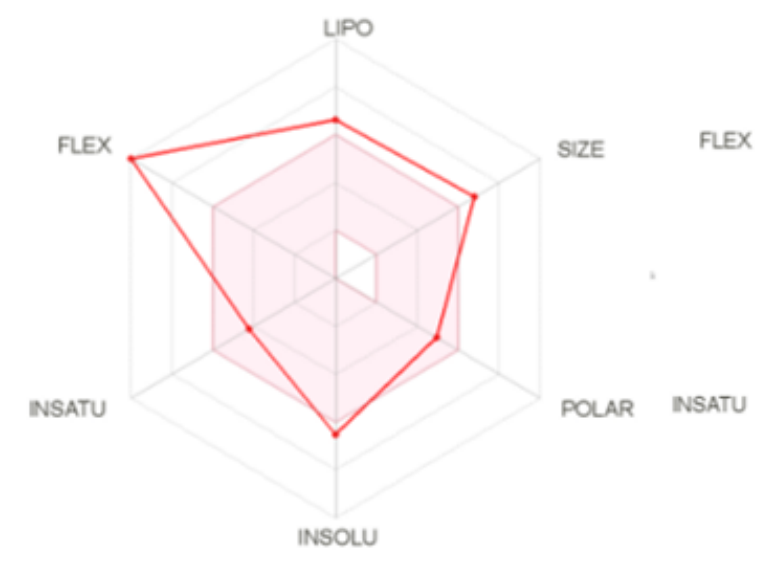

(ii) PubChem CID:88265020

(iv) PubChem CID: 71313049

Figure 12

Bioavailability radar related to physicochemical properties of two of each best compound from established docked result and virtual screened result 


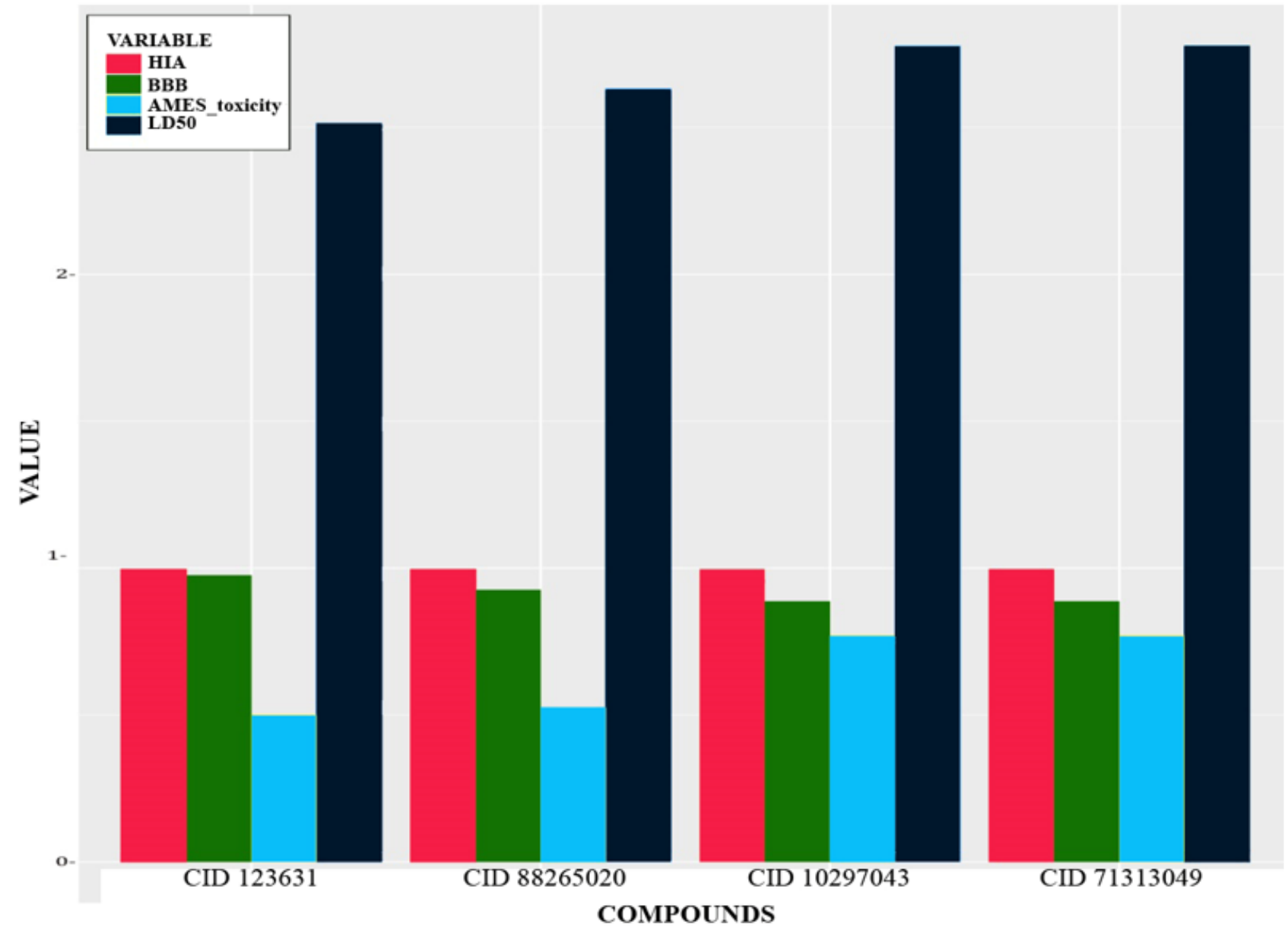

Figure 13

Comparative HIA, BBB, AMES toxicity, LD50 of the Established compounds against Virtual screened compounds 


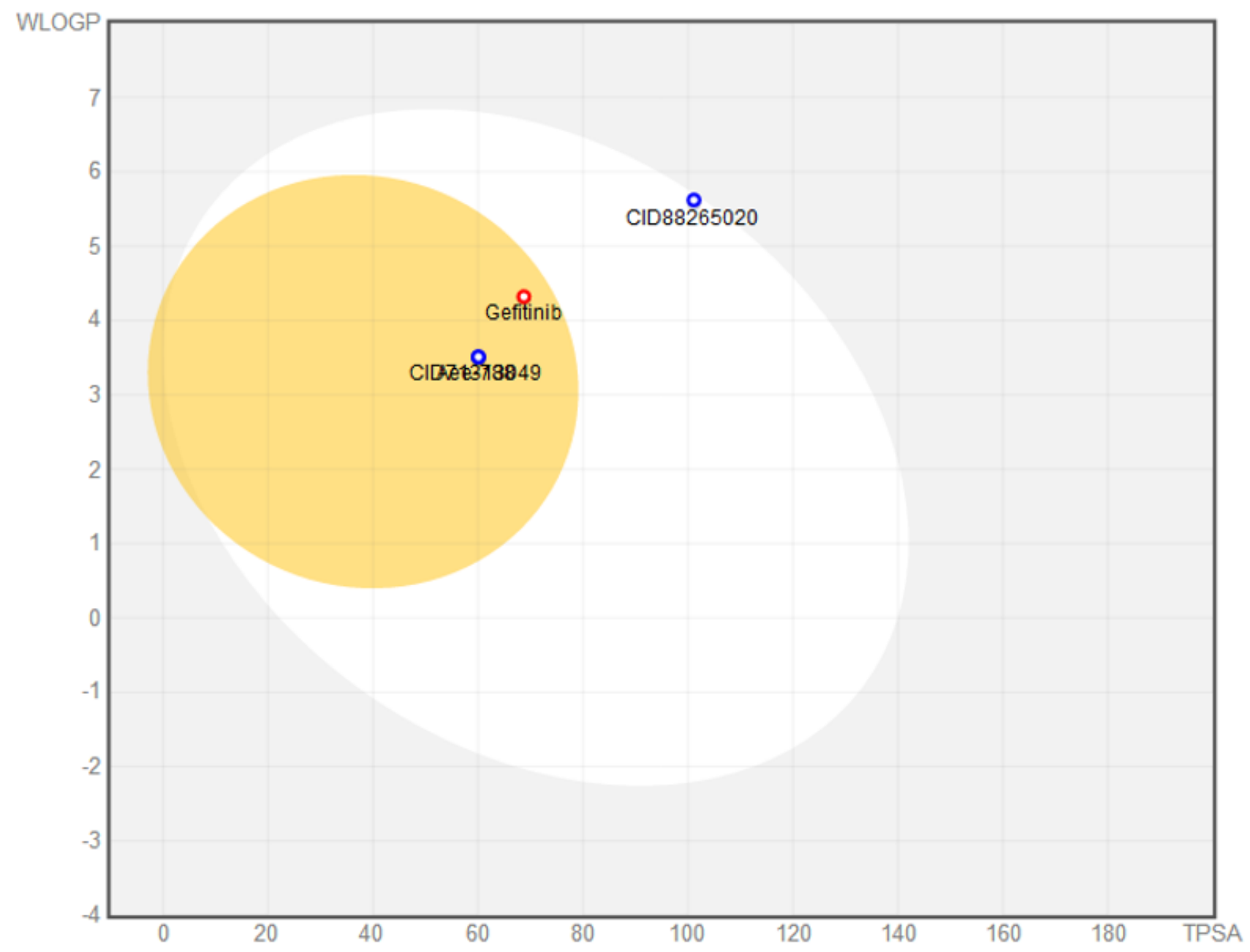

Figure 14

Boiled Egg Plot of 4 most effective Virtual Screened and Established drugs. 